\title{
Review Article \\ Oral Cavity as an Extragastric Reservoir of Helicobacter pylori
}

\author{
Arwa Al Sayed, ${ }^{1}$ Pradeep S. Anand, ${ }^{2}$ Kavitha P. Kamath, ${ }^{3}$ Shankargouda Patil, ${ }^{4}$ \\ R. S. Preethanath, ${ }^{5}$ and Sukumaran Anil $^{5}$ \\ ${ }^{1}$ Department of Dentistry, Prince Sultan Military Medical City, Ministry of Defense, P.O. Box 2993, Riyadh 11461, Saudi Arabia \\ ${ }^{2}$ Department of Periodontics, People’s College of Dental Sciences \& Research Centre, Bhopal, Madhya Pradesh 462037, India \\ ${ }^{3}$ Department of Oral Pathology, People's Dental Academy, Bhopal, Madhya Pradesh 462037, India \\ ${ }^{4}$ Department of Oral Pathology, MS Ramaiah Dental College and Hospital, Bangalore, Karnataka 560054, India \\ ${ }^{5}$ Department of Periodontics and Community Dentistry, College of Dentistry, King Saud University, P.O. Box 60169, \\ Riyadh 11545, Saudi Arabia
}

Correspondence should be addressed to Sukumaran Anil; drsanil@gmail.com

Received 11 November 2013; Accepted 24 December 2013; Published 20 February 2014

Academic Editors: N. Figura and T. Tsukamoto

Copyright (C) 2014 Arwa Al Sayed et al. This is an open access article distributed under the Creative Commons Attribution License, which permits unrestricted use, distribution, and reproduction in any medium, provided the original work is properly cited.

\begin{abstract}
Background. Several studies were reported on the prevalence, and relationship between the existence of Helicobacter pylori (H. pylori) in oral cavity and in stomach of patients. The purpose of this study was to systematically review the existing literature on the presence of $H$. pylori in the oral cavity and its link to gastric infection, the existence of coinfection, and the impact of anti- $H$. pylori therapy on the dental plaque and vice versa. Method. Two authors independently searched the Medline, EMBASE, Cochrane Library, Web of Science, Google Scholar, and Scopus databases for relevant studies. The articles were analyzed critically and all qualified studies were included. The search was carried out by using a combined text and the MeSH search strategies: using the key words Helicobacter, Helicobacter pylori, and H. pylori in combination with dental plaque, periodontitis, and oral hygiene. Results. The data was presented in 8 tables and each topic separately discussed. Conclusion. Based on the systematic review of the available literature on $H$. pylori infection and its presence in the oral cavity, it can be concluded that dental plaque can act as a reservoir, and proper oral hygiene maintenance is essential to prevent reinfection. Due to the diversified methods and population groups involved in the available literature, no concrete evidence can be laid down. Further studies are necessary to establish the role of $H$. pylori in the oral cavity and its eradication on preventing the gastroduodenal infection.
\end{abstract}

\section{Introduction}

Helicobacter pylori (H. pylori) is one of the most common bacterial infections in humans [1]. The presence of the organism H. pylori (initially termed Campylobacter pyloridis) in the antral mucosa of humans was first reported in 1983 [2]. H. pylori has been closely linked to chronic gastritis, peptic ulcer, gastric cancer, and mucosa-associated lymphoid tissue (MALT) lymphoma [3, 4]. The International Agency for Research on Cancer of the World Health Organization (WHO) has designated $H$. pylori as a Group 1 carcinogen [5]. Besides gastrointestinal diseases, recent data seems to suggest a possible association of this microorganism with other conditions such as anemia [6], altered serum levels of lipoproteins [7], and coronary atherosclerosis [8]. Although $H$. pylori is present in the stomach of about half of the world's population, we do not yet clearly understand its transmission. Available data suggests that oral-oral and fecal-oral routes are the most likely routes of transmission of this organism $[9,10]$. However, no extragastric reservoirs of $H$. pylori have been clearly demonstrated. A recent study has reported the detection of the organisms in soil samples in public playgrounds suggesting the role of the abovementioned routes in the transmission of the organism [11]. However, the likelihood of transmission of infection through contaminated soil needs to be clarified. Although organisms resembling H. pylori may be detected in other animals, none, except non-human primates [12] and cats [13], harbor $H$. pylori. Infections by Helicobacter species ( $H$. heilmannii and $H$. felis) have been reported in dogs and cats $[14,15]$. It has been suggested that the microorganism may be transmitted orally and has been detected in dental plaque and saliva [16-18]. But whether 
the oral cavity serves as an extragastric reservoir for $H$. pylori or harbors the organism only transiently, is not yet clear (the organism being only a transient inhabitant of this ecological niche or not). If the oral cavity is an extragastric reservoir of the $H$. pylori, it may be clinically significant from the treatment aspect as the microorganisms residing in the dental plaque are afforded protection from systemically administered antimicrobial agents. Treatment of $H$. pylori infection usually involves a combination of antibiotics, acid suppressors, and stomach protectors. Despite the current treatment regimens that lead to successful management of H. pylori-positive chronic gastritis, the reinfection rate is relatively high [19]. One of the suggested mechanisms of reinfection is the possible recolonization from the dental plaque [20]. A large number of studies have been carried out among various populations to determine whether dental plaque and periodontal disease are associated with $H$. pylori infection. This paper attempts to review the current evidence regarding the role of oral cavity as an extragastric reservoir of H. pylori.

\section{Materials and Methods}

2.1. Literature Search. A systematic review was conducted in January 2013. All relevant studies published between January 1990 and December 2012 were identified and included in the systematic analysis. Two authors independently searched the Medline, EMBASE, Cochrane Library, Web of Science, Google Scholar, and Scopus databases for relevant studies. The search was carried out by using a combined text and the MeSH search strategies: using the key words Helicobacter, Helicobacter pylori, and $H$. pylori in combination with dental plaque, periodontitis, and oral hygiene. We also examined the bibliographies from identified studies, reviews, and gray literature. The last search was conducted on December 31, 2012 .

2.2. Study Selection Criteria. Studies reporting the identification of Helicobacter pylori in dental plaque, coinfection of periodontitis and $H$. pylori, effect of periodontal therapy on $H$. pylori, and effect of treatment of $H$. pylori infection on periodontal problems were included in the review. The types of studies included were cross-sectional, experimental studies and interventional studies. Patients in all age groups were included. Studies presented solely in the form of abstracts in scientific conferences and studies published in languages other than English were not considered in this review.

2.3. Data Extraction Considerations. Data extracted from each of the included studies was referred to the study design, the method used to study the presence of $H$. pylori, and the type of association between the periodontal problems and $H$. pylori infection. The data was presented in a tabular form with the variables in quantitative and qualitative format.

The papers were grouped according to the content of the study and presented in 8 tables based on the date of publication of the study. Tables 1-4 depict the presence of H. pylori in dental plaque. Tables 5 and 6 enumerate the coinfection and association studies between $H$. pylori infection and periodontal disease. Table 7 shows the effect of anti-H. pylori therapy on its presence in dental plaque. Studies on the effects of periodontal treatment on $H$. pylori presence in dental plaque and gastric infection are listed are Table 8.

2.4. Methods of Detection of H. pylori. Various methods have been employed to detect the presence of the bacterium $H$. pylori in the gastrointestinal mucosa. These include histology, culture, urease test, serologic tests, urea breath test, and polymerase chain reaction targeting specific nuclear material of the microorganism [3]. Histological methods using conventional hematoxylin and eosin staining can be used to visualize $H$. pylori while use of special stains such WarthinStarry and Giemsa staining can enhance the histologic identification of the microorganism. By employing culture methods, antimicrobial susceptibility tests can be performed. Urease tests and urea breath tests are based on the fact that the microorganisms are associated with large amounts of urease activity while serologic tests detect the levels of antibodies such as IgG and IgA in the serum that is elevated in response to an infection by $H$. pylori. Several different polymerase chain reaction (PCR) methods which differ in their target DNA have been developed for the diagnosis of $H$. pylori infection and these can help to differentiate between $H$. pylori strains.

2.5. H. pylori in Dental Plaque. The prevalence of H. pylori in the dental plaque has been studied by several investigators. The results of these studies showed wide variation and this seems to depend at least in part on the method employed to detect the bacterium in the dental plaque. As mentioned earlier, investigators have used several methods to detect the presence of the bacterium in the dental plaque and these include urease tests (rapid urease/CLO test), PCR, histology, culture, and immunoassays.

2.6. Prevalence Data as Reported in Studies Utilizing Urease Tests. The prevalence of $H$. pylori in the dental plaque of study participants reported by investigators using urease tests is given in Table 1 . The prevalence of $H$. pylori in dental plaque in these studies generally ranged from $50 \%$ to $100 \%$ except in 3 studies. In 2 of these studies the prevalence rates reported were $44.8 \%$ [21] and 43\% [22] while the lowest rate reported was $18.2 \%$ [23].

2.7. Prevalence Data as Reported in Studies Utilizing PCR. The prevalence of $H$. pylori in the dental plaque of study participants reported by investigators using PCR is given in Table 2 . The prevalence rates reported in these studies ranged from $0-100 \%$ and were generally lower than those reported in studies in which urease tests were used to detect the presence of $H$. pylori in dental plaque. However, out of the 34 studies reviewed in this category, only 7 studies reported a prevalence rate exceeding $50 \%$. Of these 7 studies, 6 were conducted amongst Asian populations. 
TABLE 1: Summary of studies in which the presence of $H$. pylori in dental plaque was determined by rapid urease test/CLO test.

\begin{tabular}{|c|c|c|c|c|}
\hline No. & Author(s) & Year & Sample size & $\begin{array}{c}\text { Prevalence of } \\
\text { H. pylori }\end{array}$ \\
\hline 1 & Assumpção et al. [48] & 2010 & $\begin{array}{l}99 \text { adult patients who underwent upper } \\
\text { gastrointestinal endoscopy }\end{array}$ & $52 \%$ \\
\hline 2 & Al Asqah et al. [35] & 2009 & $\begin{array}{l}\text { Sixty-two dyspeptic patients with } \\
\text { periodontitis and } 39 \text { dyspeptic patients } \\
\text { without periodontitis }\end{array}$ & $\begin{array}{c}\text { Overall-65\%; } 79 \% \\
\text { in periodontitis } \\
\text { group and } 43 \% \text { in } \\
\text { nonperiodontitis } \\
\text { group }\end{array}$ \\
\hline 3 & Anand et al. [38] & 2006 & $\begin{array}{l}\text { Sixty-five dyspeptic patients with } H \text {. } \\
\text { pylori infection (cases) and } 69 \text { dyspeptic } \\
\text { patients without } H \text {. pylori infection } \\
\text { (control) }\end{array}$ & $\begin{array}{c}\text { Overall-79.9\%; } \\
89 \% \text { among cases } \\
\text { and } 71 \% \text { among } \\
\text { controls }\end{array}$ \\
\hline 4 & Chitsazi et al. [23] & 2006 & $\begin{array}{l}88 \text { dyspeptic patients- } 44 \text { with } H \text {. pylori } \\
\text { infection and } 44 \text { without } H \text {. pylori } \\
\text { infection }\end{array}$ & $\begin{array}{l}\text { Overall } 18.2 \% \\
36.4 \% \text { in } \mathrm{HP} \\
\text { positive group }\end{array}$ \\
\hline 5 & Choudhury et al. [22] & 2003 & 124 patients with dyspepsia & $43 \%$ \\
\hline 6 & Gürbüz et al. [30] & 2003 & 75 dyspeptic patients & $91.7 \%$ \\
\hline 7 & Suk et al. [45] & 2002 & $\begin{array}{l}\text { Sixty-five patients with dyspeptic } \\
\text { symptoms }\end{array}$ & $100 \%$ \\
\hline 8 & Avcu et al. [21] & 2001 & $\begin{array}{l}241 \mathrm{H} \text {. pylori positive patients with gastric } \\
\text { histologic changes }\end{array}$ & $44.8 \%$ \\
\hline 9 & Özdemir et al. [49] & 2001 & 81 dyspeptic patients & $79 \%$ \\
\hline 10 & Qureshi et al. [50] & 1999 & 60 dyspeptic patients & $50 \%$ \\
\hline 11 & Contractor et al. [51] & 1998 & 100 healthy subjects & $81 \%$ \\
\hline
\end{tabular}

2.8. Prevalence Data as Reported in Studies Utilizing Culture. The prevalence of $H$. pylori in the dental plaque reported by investigators using culture method is given in Table 3. The prevalence rates reported in these studies were generally below $50 \%$ with about half studies reported less than $10 \%$ prevalence. In 2 of these studies [24, 25], the microorganism could not be cultured from the dental plaque.

2.9. Prevalence Data as Reported in Studies Utilizing Immunoassays. The prevalence of $H$. pylori in the dental plaque reported by investigators using immunoassays is given in Table 4. Using this method for detection of H. pylori in dental plaque, 2 studies $[26,27]$ reported a high prevalence $(>65 \%)$ of the microorganism in dental plaque while other 2 studies $[28,29]$ reported a very low prevalence (0 and $11 \%)$.

\subsection{Prevalence of Coinfection of Gastric Mucosa and Dental} Plaque by $H$. pylori. The summary of studies which have evaluated the prevalence of coinfection of gastric mucosa and dental plaque by $H$. pylori among the study participants is given in Table 5. The prevalence rate of coinfection among the respective study populations reported by different investigators ranged from as low as $1 \%$ to as high as $82.1 \%$. This wide variation in the prevalence rates of coinfection may be partly due to the difference in the diagnostic tests employed by various investigators to detect the bacterium in the dental plaque. Studies utilizing urease tests to detect the presence of the microorganism in the dental plaque have reported very high prevalence rates. Except for one study which reported a $25.2 \%$ prevalence of coinfection, all the other studies utilizing urease tests have reported a coinfection rate in excess of $32 \%$, with one study reporting a prevalence rate of $81.3 \%$ [30]. In studies involving PCR, the prevalence rates have ranged between $0 \%$ and $47.6 \%$ with only 5 out of the 11 studies reporting a prevalence rate above $30 \%$. Low rates of prevalence of coinfection were reported when microbial culture was employed to detect $H$. pylori from the dental plaque. Out of the 5 studies reviewed which employed microbial culture, the rates of prevalence reported were $1 \%$, $1.4 \%, 6.9 \%, 14.6 \%$, and $18 \%$, respectively $[16,31-33]$. In the 2 studies reviewed which used immunoassays for detection of pathogen in dental plaque samples, the prevalence rates reported were $23.6 \%$ and $47.6 \%$ [27]. Among patients with gastrointestinal colonization by $H$. pylori, the prevalence of coinfection in dental plaque was reported to be in the range of $25.2 \%$ to $100 \%$. In studies involving the use of urease test only 2 out of the 8 studies reported a prevalence rate of less than $50 \%$; $0 \%$ to $100 \%$ in PCR studies with 5 out of the 11 studies reviewed reported a prevalence rate above $50 \% ; 1.7 \%$ to $30 \%$ in the 5 studies using microbial culture; and $23.6 \%$ to $82.1 \%$ in studies using immunoassays.

2.11. H. pylori and Periodontal Disease. Few studies have evaluated the relationship between gingival and periodontal disease and $H$. pylori infection. While some investigators $[34,35]$ have reported a positive association between the two conditions, others have reported that there was no association between $H$. pylori infection and periodontal diseases $[18,36]$. 
TABLE 2: Summary of studies in which the presence of $H$. pylori in dental plaque was determined by PCR.

\begin{tabular}{|c|c|c|c|c|c|}
\hline No. & Authors & Year & Target gene & Sample size & Prevalence of $H$. pylori \\
\hline 1 & Momtaz et al. [52] & 2012 & $\begin{array}{l}\text { ureC, cagA, } \\
\text { and vacA }\end{array}$ & $\begin{array}{l}300 \text { patients with } \\
\text { gastroduodenal diseases }\end{array}$ & $\begin{array}{l}\text { None of the plaque samples } \\
\text { showed presence of } H \text {. } \\
\text { pylori }\end{array}$ \\
\hline 2 & $\begin{array}{l}\text { Agarwal and } \\
\text { Jithendra [31] }\end{array}$ & 2012 & 16S rRNA & $\begin{array}{l}30 \mathrm{H} . \text { pylori positive and } \\
20 \mathrm{H} . \text { pylori negative } \\
\text { patients }\end{array}$ & $\begin{array}{l}\text { Overall- } 42 \% \text {; in } H . \text { pylori } \\
\text { positive group- } 60 \% \text {; in } H \text {. } \\
\text { pylori negative group- } 15 \% .\end{array}$ \\
\hline 3 & Bago et al. [41] & 2011 & $16 \mathrm{~S}$ rDNA & $\begin{array}{l}56 \text { patients with chronic } \\
\text { periodontitis and gastric } \\
\text { H. pylori positive }\end{array}$ & $37.5 \%$ \\
\hline 4 & Chaudhry et al. [53] & 2011 & $\begin{array}{l}\text { 16srRNA and } \\
860 \text { bp DNA } \\
\text { region }\end{array}$ & $\begin{array}{l}89 \text { dyspeptic patients } \\
\text { reporting for endoscopy }\end{array}$ & $\begin{array}{l}51.6 \% \text { for both genes; } 62.9 \% \\
\text { for } 16 \text { srRNA; } 61 \% \text { for } \\
860 \text { bp DNA region and } \\
73 \% \text { if either of the } 2 \\
\text { regions are considered }\end{array}$ \\
\hline 5 & Gao et al. [44] & 2011 & $\begin{array}{l}\text { ureC and } \\
\text { cagA genes }\end{array}$ & $\begin{array}{l}96 \text { patients with } H . \\
\text { pylori infection }\end{array}$ & $82.3 \%$ \\
\hline 6 & Wichelhaus et al. [54] & 2011 & 860bp DNA & 11 orthodontic patients & $36 \%$ \\
\hline 7 & Assumpção et al. [48] & 2010 & $\begin{array}{l}\operatorname{vacA} \text { and } \\
\operatorname{cagA}\end{array}$ & $\begin{array}{l}99 \text { adult patients who } \\
\text { underwent upper } \\
\text { gastrointestinal } \\
\text { endoscopy }\end{array}$ & $\begin{array}{l}72 \% \text { samples were positive } \\
\text { for } H \text {. pylori. } 63 \text { of } 71 \\
\text { positive dental plaque } \\
\text { samples were positive for } \\
\text { vacA and cagA. } 58 / 71 \text { were } \\
\text { positive for cagA while } \\
\text { vacA genotypes had a } \\
\text { prevalence ranging from } \\
13-59 \%\end{array}$ \\
\hline 8 & Rasmussen et al. [55] & 2010 & $\begin{array}{c}\text { Genomic } \\
\text { DNA }\end{array}$ & 78 dyspeptic patients & $47.4 \%$ \\
\hline 9 & Eskandari et al. [56] & 2010 & $16 \mathrm{~S}$ rRNA & $\begin{array}{l}67 \text { patients with chronic } \\
\text { periodontitis- } 23 \text { with } H \text {. } \\
\text { pylori positive gastritis }\end{array}$ & $5.97 \%$ \\
\hline 10 & Silva et al. [57] & 2010 & $\begin{array}{c}\text { vacA and } 16 \mathrm{~S} \\
\text { rDNA }\end{array}$ & 30 dyspeptic patients & $\begin{array}{l}20 \% \text { by } 16 \mathrm{~S} \text { rDNA and } 6.7 \% \\
\text { by vacA }\end{array}$ \\
\hline 11 & Silva et al. [58] & 2010 & 16S rRNA & 115 patients & $11.3 \%$ \\
\hline 12 & Silva et al. [59] & 2009 & $\begin{array}{l}\text { 16s ribosomal } \\
\text { and cagA } \\
\text { genes }\end{array}$ & $\begin{array}{l}32 \text { with } H \text {. pylori positive } \\
\text { with gastric disease and } \\
32 \text { with } H \text {. pylori positive } \\
\text { with no gastric disease }\end{array}$ & $\begin{array}{l}\text { Overall- } 17.7 \% \text {. Among } \\
\text { cases, } H \text {. pylori DNA } \\
\text { detected in } 36.6 \% \text { and cagA } \\
\text { gene detected in } 3 \text { out of } 11 \\
(27.3 \%) \text { samples. In control } \\
\text { group } 0 \%\end{array}$ \\
\hline 13 & $\begin{array}{l}\text { Gonçalves } \\
\text { et al. [60] }\end{array}$ & 2009 & $\begin{array}{l}\text { JW22 and } \\
\text { JW23 } \\
\text { primers/16S } \\
\text { rRNA }\end{array}$ & $\begin{array}{l}\text { 23, HIV seropositive } \\
\text { individuals of whom } 13 \\
\text { with chronic } \\
\text { periodontitis and } 10 \text { with } \\
\text { periodontally healthy } \\
\text { and } 31 \text { HIV seronegative } \\
\text { individuals of whom } 17 \\
\text { had chronic } \\
\text { periodontitis and } 14 \text { were } \\
\text { periodontally healthy }\end{array}$ & Not specified \\
\hline 14 & Liu et al. [61] & 2009 & $\begin{array}{l}860 \mathrm{bp} \\
\text { fragment }\end{array}$ & 443 dyspeptic patients & $59.4 \%$ \\
\hline 15 & Bürgers et al. [36] & 2008 & $16 \mathrm{~S}$ rDNA & $\begin{array}{l}94 \text { patients who } \\
\text { underwent upper } \\
\text { gastrointestinal } \\
\text { endoscopy }\end{array}$ & $5.4 \%$ \\
\hline 16 & Liu et al. [62] & 2008 & $\begin{array}{c}860 \mathrm{bp} \\
\text { fragment }\end{array}$ & 214 children & $58.9 \%$ \\
\hline
\end{tabular}


TABLe 2: Continued.

\begin{tabular}{|c|c|c|c|c|c|}
\hline No. & Authors & Year & Target gene & Sample size & Prevalence of $H$. pylori \\
\hline 17 & Teoman et al. [25] & 2007 & & 67 dyspeptic patients & $28.3 \%$ \\
\hline 18 & Olivier et al. [63] & 2006 & $\begin{array}{l}\text { urease } \mathrm{AB} \\
\text { gene; } \\
\text { phosphoglu- } \\
\text { cosamine } \\
\text { mutase } \\
(\text { glmM }) \text { gene; } \\
\text { and } 860 \text { bp } \\
\text { DNA region }\end{array}$ & $\begin{array}{l}74 \text { healthy members of a } \\
\text { rural community }\end{array}$ & 0 \\
\hline 19 & Kignel et al. [64] & 2005 & 16S rRNA & 49 dyspeptic patients & $2 \%$ \\
\hline 20 & Fritscher et al. [65] & 2004 & $\begin{array}{l}860 \mathrm{bp} \\
\text { fragment }\end{array}$ & $\begin{array}{l}53 \text { patients with } \\
\text { recurrent aphthous } \\
\text { stomatitis and } 52 \\
\text { patients without RAS }\end{array}$ & $\begin{array}{l}\text { Overall- } 3.8 \% ; 5.7 \% \text { in cases } \\
\text { and } 1.9 \% \text { among controls }\end{array}$ \\
\hline 21 & Gebara et al. [66] & 2004 & $16 \mathrm{~S}$ rDNA & $\begin{array}{l}30 \text { dentate patients with } \\
\text { gingivitis/periodontitis } \\
\text { and } H \text {. pylori infection }\end{array}$ & $\begin{array}{l}20 \% \text { in supra-gingival } \\
\text { plaque and } 26.6 \% \text { in } \\
\text { subgingival plaque }\end{array}$ \\
\hline 22 & Umeda et al. [37] & 2003 & 16S rRNA & 56 dental patients & $25 \%$ \\
\hline 23 & Goosen et al. [67] & 2002 & & & \\
\hline 24 & Berroteran et al. [39] & 2002 & Urease genes & $\begin{array}{l}32 \text { dyspeptic patients } \\
\text { and } 20 \text { asymptomatic } \\
\text { controls }\end{array}$ & $\begin{array}{l}\text { Overall-28.9\%; } 37.5 \% \\
\text { among dyspeptic patients } \\
\text { and } 15 \% \text { among controls }\end{array}$ \\
\hline 25 & Suk et al. [45] & 2002 & cagA & $\begin{array}{l}\text { Sixty-five patients with } \\
\text { dyspeptic symptoms }\end{array}$ & $43.1 \%$ \\
\hline 26 & $\begin{array}{c}\text { Miyabayashi et al. } \\
{[43]}\end{array}$ & 2000 & ureA & $\begin{array}{l}47 \text { patients with chronic } \\
\text { gastritis or peptic ulcer }\end{array}$ & $38.3 \%$ \\
\hline 27 & Song et al. [68] & 2000 & $\begin{array}{l}860 \mathrm{bp} \\
\text { fragment }\end{array}$ & $\begin{array}{l}\text { Forty-two patients who } \\
\text { underwent upper } \\
\text { gastrointestinal } \\
\text { endoscopy }\end{array}$ & $\begin{array}{l}\text { Overall } 97 \% \text { ( } 82 \% \text { in molar } \\
\text { region, } 64 \% \text { in premolar } \\
\text { region and } 59 \% \text { in incisor } \\
\text { region) }\end{array}$ \\
\hline 28 & Song et al. [69] & 2000 & $\begin{array}{l}860 \mathrm{bp} \\
\text { fragment }\end{array}$ & 20 dyspeptic patients & Not specified \\
\hline 29 & Song et al. [70] & 2000 & $\begin{array}{c}860 \mathrm{bp} \\
\text { fragment }\end{array}$ & 21 patients & $100 \%$ \\
\hline 30 & Song et al. [71] & 1999 & $\begin{array}{l}\text { Urease A, 16S } \\
\text { rRNA, and } \\
860 \text { bp } \\
\text { fragment }\end{array}$ & 40 dental patients & \\
\hline 31 & Dowsett et al. [18] & 1999 & & & Not specified \\
\hline 32 & Oshowo et al. [32] & 1998 & 16S rRNA & $\begin{array}{l}208 \text { dyspeptic } \\
\text { patients-116 H. pylori } \\
\text { positive and } 92 \mathrm{H} \text {. pylori } \\
\text { negative }\end{array}$ & $\begin{array}{l}\text { Overall } 6.25 \% \text { all in } H . \\
\text { pylori positive }\end{array}$ \\
\hline 33 & Hardo et al. [24] & 1995 & 16S rRNA & 62 dyspeptic patients & $1.6 \%$ \\
\hline 34 & Mapstone et al. [72] & 1993 & 16S rRNA & $\begin{array}{l}21 \text { dyspeptic patients- } 13 \\
\text { with } H \text {. pylori associated } \\
\text { gastritis and } 8 \text { who had } \\
\text { normal histology }\end{array}$ & $\begin{array}{l}\text { Overall-9.5\%; } 15.4 \% \text { in } \\
\text { gastritis group and } 0 \text { in } \\
\text { histologically normal } \\
\text { group-overall } \\
\text { prevalence-9.5\% }\end{array}$ \\
\hline 35 & Nguyen et al. [73] & 1993 & 16S rRNA & 25 dyspeptic patients & $\begin{array}{l}\text { Overall } 28 \% \text { all in } H \text {. pylori } \\
\text { positive; among } H \text {. pylori } \\
\text { positive individuals } 38.8 \% \text {. }\end{array}$ \\
\hline
\end{tabular}


TABLE 3: Summary of studies in which the presence of $H$. pylori in dental plaque was determined by culture.

\begin{tabular}{|c|c|c|c|c|}
\hline No. & Authors & Year & Sample size & $\begin{array}{c}\text { Prevalence of } \\
\text { H. pylori }\end{array}$ \\
\hline 1 & Agarwal and Jithendra [31] & 2012 & $\begin{array}{l}30 \mathrm{H} . \text { pylori positive and } 20 \\
\text { H. pylori negative patients }\end{array}$ & $\begin{array}{c}\text { Overall-18\%; in } H . \\
\text { pylori positive } \\
\text { group-30\%; in } H . \\
\text { pylori negative } \\
\text { group-0 }\end{array}$ \\
\hline 2 & Loster et al. [74] & 2009 & $\begin{array}{l}\text { Forty six dentists without } \\
\text { known co-morbidities }\end{array}$ & $48 \%$ \\
\hline 3 & Teoman et al. [25] & 2007 & 67 dyspeptic patients & 0 \\
\hline 4 & Czesnikiewicz-Guzik et al. [75] & 2005 & 100 female patients & $48.3 \%$ \\
\hline 5 & Cześnikiewicz-Guzik et al. [33] & 2004 & 100 female patients & $48.3 \%$ \\
\hline 6 & Umeda et al. [37] & 2003 & 18 dental patients & $5.6 \%$ \\
\hline 7 & Goosen et al. [67] & 2002 & $\begin{array}{l}58 \text { clinically healthy } \\
\text { volunteers }\end{array}$ & $\begin{array}{l}13.8 \% \text { of which } \\
\text { only } 5.2 \% \text { were } \\
\text { positive in PCR } \\
\text { analysis }\end{array}$ \\
\hline 8 & Checchi et al. [28] & 2000 & $\begin{array}{l}35 \text { patients from a } \\
\text { Periodontology clinic }\end{array}$ & $8.6 \%$ \\
\hline 9 & Oshowo et al. [32] & 1998 & $\begin{array}{l}208 \text { dyspeptic patients- } 116 \\
\text { H. pylori positive and } 92 \mathrm{H} \text {. } \\
\text { pylori negative }\end{array}$ & $\begin{array}{l}\text { Overall } 1 \% \text { all in } H . \\
\text { pylori positive }\end{array}$ \\
\hline 10 & Hardo et al. [24] & 1995 & 62 dyspeptic patients & 0 \\
\hline 11 & Krajden et al. [16] & 1989 & $\begin{array}{l}71 \text { patients undergoing } \\
\text { endoscopy }\end{array}$ & $1.4 \%$ \\
\hline
\end{tabular}

TABLE 4: Summary of studies in which the presence of $H$. pylori in dental plaque was determined by EIA.

\begin{tabular}{|c|c|c|c|c|}
\hline No. & Authors & Year & Sample size & Prevalence of H. pylori \\
\hline 1 & Namiot et al. [26] & 2010 & 155 patients & $65.6 \%$ \\
\hline 2 & Leszczyńska et al. [27] & 2009 & $\begin{array}{l}164 \text { dyspeptic patients referred for } \\
\text { endoscopy- } 95 \mathrm{H} \text {. pylori infected and } 69 \\
\text { noninfected }\end{array}$ & $\begin{array}{l}82.1 \% \text { in } H . \text { pylori } \\
\text { positive subjects and } \\
17.7 \% \text { in } H . \text { pylori } \\
\text { negative subjects }\end{array}$ \\
\hline 3 & Checchi et al. [28] & 2000 & 35 patients from a Periodontology clinic & $11 \%$ \\
\hline 4 & Savoldi et al. [29] & 1998 & 80 dyspeptic patients & 0 \\
\hline
\end{tabular}

Table 6 shows the studies which have evaluated the relationship between periodontal disease and $H$. pylori infection.

A large-scale epidemiological study which evaluated the relationship between $H$. pylori infection and abnormal periodontal conditions by Dye et al. [34] utilized the data from the first phase of the third National Health and Nutrition Examination Survey. A total of 4504 participants aged 20 to 59 years who completed a periodontal examination and tested positive for $H$. pylori antibodies were examined. Periodontal pockets with a depth of $5 \mathrm{~mm}$ or more were associated with increased odds of $H$. pylori seropositivity after adjustment for sociodemographic factors. The authors reported that this association is comparable to the independent effects of poverty on $H$. pylori and concluded that poor periodontal health, characterized by advanced periodontal pockets, may be associated with $H$. pylori infection in adults, independent of poverty status.
Nested polymerase chain reaction (PCR) was employed by Umeda et al. [37] to clarify whether the oral cavity acts as a reservoir for $H$. pylori. The existence of $H$. pylori in the oral cavity was determined by nested PCR in 57 subjects and by culture method in 18 subjects. The presence of periodontopathic bacteria was also determined by $16 \mathrm{~S}$ rRNA-based PCR method. Although $H$. pylori was rarely detected in the oral cavity by culture technique, it was frequently detected (35.1\%) by nested PCR, especially among periodontitis patients who had the bacterium in the gastrointestinal tract (46.4\%). Among the subjects who harbored H. pylori in the stomach or duodenum, $41.2 \%$ of patients with periodontal pockets $\geq 4 \mathrm{~mm}$ and $9.1 \%$ of subjects without periodontal pockets showed H. pylori in dental plaque. They also reported that one patient who had periodontal pockets retained $H$. pylori in the oral cavity even after eradication of the bacterium from the stomach and duodenum. Most (8/10) of the patients who 
TABLE 5: Data regarding the coinfection of $H$. pylori and oral infection.

\begin{tabular}{|c|c|c|c|c|c|}
\hline No. & Authors & Year & $\begin{array}{l}\text { Method used to } \\
\text { detect H. pylori }\end{array}$ & Sample size & $\begin{array}{c}\text { Prevalence of } \\
\text { coinfection of } H . \text { pylori }\end{array}$ \\
\hline 1 & $\begin{array}{l}\text { Agarwal and } \\
\text { Jithendra [31] }\end{array}$ & 2012 & PCR-16S rRNA & $\begin{array}{l}30 \mathrm{H} \text {. pylori positive and } 20 \\
\text { H. pylori negative patients }\end{array}$ & $\begin{array}{l}\text { Overall-36\%; in H. pylori } \\
\text { positive group- } 60 \%\end{array}$ \\
\hline 2 & $\begin{array}{l}\text { Agarwal and } \\
\text { Jithendra [31] }\end{array}$ & 2012 & Culture & $\begin{array}{l}30 \mathrm{H} \text {. pylori positive and } 20 \\
\text { H. pylori patients }\end{array}$ & $\begin{array}{l}\text { Overall-18\%; in H. pylori } \\
\text { positive group-30\% }\end{array}$ \\
\hline 3 & Bago et al. [41] & 2011 & PCR-16S rDNA & $\begin{array}{l}56 \text { patients with chronic } \\
\text { periodontitis and gastric } H \text {. } \\
\text { pylori positive }\end{array}$ & $37.5 \%$ \\
\hline 4 & Silva et al. [58] & 2010 & PCR-16S rRNA & 115 patients & $\begin{array}{l}\text { Overall- } 8.7 \% \text {; among } H \text {. } \\
\text { pylori positive } \\
\text { group- } 14.93 \%\end{array}$ \\
\hline 5 & $\begin{array}{c}\text { Eskandari et al. } \\
{[56]}\end{array}$ & 2010 & PCR-16S rRNA & $\begin{array}{l}67 \text { patients with chronic } \\
\text { periodontitis- } 23 \text { with } H \text {. } \\
\text { pylori positive gastritis }\end{array}$ & $\begin{array}{l}\text { Overall-5.97\%; among } \\
\text { H. pylori positive } \\
\text { group- } 17.39 \%\end{array}$ \\
\hline 6 & $\begin{array}{l}\text { Al Asqah et al. } \\
{[35]}\end{array}$ & 2009 & RUT & $\begin{array}{l}62 \text { dyspeptic patients with } \\
\text { periodontitis and } 39 \\
\text { dyspeptic patients without } \\
\text { periodontitis }\end{array}$ & $\begin{array}{c}\text { Overall-32.7\%; } 66 \% \\
\text { among H. pylori positive } \\
\text { patients }\end{array}$ \\
\hline 7 & Liu et al. [61] & 2009 & $\begin{array}{l}\text { PCR-860-bp } \\
\text { fragment }\end{array}$ & 443 dyspeptic patients & $\begin{array}{l}\text { Overall- } 42.7 \% \text {; among } \\
H . \text { pylori positive } \\
\text { subjects-69.2\% }(75.5 \% \text { in } \\
18-29 \text { years; } 61.7 \% \text { in } \\
30-39 \text { years; } 79.7 \% \text { in } \\
40-49 \text { years; } 76.6 \% \text { in } \\
\geq 50 \text { years) }\end{array}$ \\
\hline 8 & $\begin{array}{l}\text { Leszczyńska } \\
\text { et al. [27] }\end{array}$ & 2009 & EIA & $\begin{array}{l}164 \text { dyspeptic patients } \\
\text { referred for endoscopy- } 95 \\
\text { H. pylori positive and } 69 \\
\text { noninfected }\end{array}$ & $\begin{array}{l}\text { Overall- } 47.6 \% ; 82.1 \% \text { in } \\
\text { H. pylori positive }\end{array}$ \\
\hline 9 & Silva et al. [59] & 2009 & $\begin{array}{l}\text { PCR-16s ribosomal } \\
\text { and cagA genes }\end{array}$ & $\begin{array}{l}30 \text { with } H \text {. pylori positive } \\
\text { with gastric disease and } 32 \\
\text { with } H \text {. pylori positive with } \\
\text { no gastric disease }\end{array}$ & $\begin{array}{l}\text { Overall-17.7\%. Among } \\
\text { cases, } H \text {. pylori DNA } \\
\text { detected in } 36.6 \% \text {, and } \\
\text { cagA gene detected in } 3 \\
\text { out of } 11 \text { samples. In } \\
\text { control group-0\% }\end{array}$ \\
\hline 10 & $\begin{array}{l}\text { Bürgers et al. } \\
{[36]}\end{array}$ & 2008 & PCR-16S rDNA & $\begin{array}{l}94 \text { patients who underwent } \\
\text { upper gastrointestinal } \\
\text { endoscopy }\end{array}$ & $\begin{array}{l}\text { Overall-1.1\% 3.5\% of } H \text {. } \\
\text { pylori positive subjects }\end{array}$ \\
\hline 11 & $\begin{array}{l}\text { Teoman et al. } \\
{[25]}\end{array}$ & 2007 & PCR-Urease A & 67 dyspeptic patients & $\begin{array}{l}\text { Overall-25.4\%; among } \\
\text { H. pylori positive } \\
\text { group-36.2\% }\end{array}$ \\
\hline 12 & $\begin{array}{c}\text { Anand et al. } \\
{[38]}\end{array}$ & 2006 & RUT & $\begin{array}{l}\text { Sixty-five dyspeptic patients } \\
\text { with } H \text {. pylori infection and } \\
69 \text { dyspeptic patients } \\
\text { without } H \text {. pylori infection }\end{array}$ & $\begin{array}{l}\text { Overall- } 43.3 \% ; 89.2 \% \\
\text { among cases }\end{array}$ \\
\hline 13 & $\begin{array}{l}\text { Chitsazi et al. } \\
\text { [23] }\end{array}$ & 2006 & RUT & $\begin{array}{l}88 \text { dyspeptic patients- } 44 \\
\text { with } H \text {. pylori infection and } \\
44 \text { without } H \text {. pylori } \\
\text { infection }\end{array}$ & $\begin{array}{l}\text { Overall } 34.1 \% ; 36.4 \% \text { in } \\
\text { H. pylori positive group }\end{array}$ \\
\hline 14 & $\begin{array}{l}\text { Agüloğlu et al. } \\
{[76]}\end{array}$ & 2006 & CLO test & $\begin{array}{l}468 \text { patients who were } H \text {. } \\
\text { pylori positive by CLO test }\end{array}$ & $25.2 \%$ \\
\hline 15 & $\begin{array}{c}\text { Agüloğlu et al. } \\
{[76]}\end{array}$ & 2006 & EIA & $\begin{array}{l}318 \text { patients who were } H \text {. } \\
\text { pylori positive by EIA }\end{array}$ & $23.6 \%$ \\
\hline 16 & $\begin{array}{c}\text { Agüloğlu et al. } \\
{[76]}\end{array}$ & 2006 & Culture & $\begin{array}{l}295 \text { patients who were } H \text {. } \\
\text { pylori positive by culture }\end{array}$ & $14.6 \%$ \\
\hline
\end{tabular}


TABle 5: Continued.

\begin{tabular}{|c|c|c|c|c|c|}
\hline No. & Authors & Year & $\begin{array}{l}\text { Method used to } \\
\text { detect H. pylori }\end{array}$ & Sample size & $\begin{array}{c}\text { Prevalence of } \\
\text { coinfection of } H \text {. pylori }\end{array}$ \\
\hline 17 & $\begin{array}{l}\text { Czesnikiewicz- } \\
\text { Guzik et al. } \\
\text { [75] }\end{array}$ & 2005 & Culture & 100 female patients & $6.9 \%$ \\
\hline 18 & $\begin{array}{l}\text { Kignel et al. } \\
{[64]}\end{array}$ & 2005 & PCR-16S rRNA & 49 dyspeptic patients & $\begin{array}{l}2 \% \text { of the total } \\
\text { population and } 5 \% \text { of } H . \\
\text { pylori positive subjects }\end{array}$ \\
\hline 19 & $\begin{array}{l}\text { Umeda et al. } \\
\text { [37] }\end{array}$ & 2003 & PCR-16S rRNA & 56 dental patients & $\begin{array}{c}\text { Overall-14.3\%; among } H \text {. } \\
\text { pylori positive } \\
\text { group- } 28.6 \% .\end{array}$ \\
\hline 20 & $\begin{array}{l}\text { Gürbüz et al. } \\
{[30]}\end{array}$ & 2003 & RUT & 75 dyspeptic patients & $\begin{array}{c}\text { Overall-81.3\%; among } H \text {. } \\
\text { pylori positive } \\
\text { subjects- } 93.9 \%\end{array}$ \\
\hline 21 & $\begin{array}{l}\text { Berroteran et } \\
\text { al. [39] }\end{array}$ & 2002 & PCR-Urease genes & $\begin{array}{l}32 \text { dyspeptic patients and } \\
20 \text { asymptomatic controls }\end{array}$ & $\begin{array}{c}\text { Overall-13.5\%; } 58 \% \\
\text { among dyspeptic } \\
\text { patients }\end{array}$ \\
\hline 22 & Suk et al. [45] & 2002 & PCR-cagA & $\begin{array}{l}65 \text { patients with dyspeptic } \\
\text { symptoms }\end{array}$ & $\begin{array}{c}\text { Overall- } 43.1 \%, 73.7 \% \\
\text { among } H . \text { pylori positive } \\
\text { patients }\end{array}$ \\
\hline 23 & Suk et al. [45] & 2002 & RUT & $\begin{array}{l}65 \text { patients with dyspeptic } \\
\text { symptoms }\end{array}$ & $\begin{array}{l}\text { Overall- } 58.5 \%, 100 \% \\
\text { among } H \text {. pylori positive } \\
\text { patients }\end{array}$ \\
\hline 24 & $\begin{array}{l}\text { Özdemir et al. } \\
{[49]}\end{array}$ & 2001 & CLO test & 81 dyspeptic patients & $\begin{array}{l}\text { Overall- } 64.2 \% \text {; among } \\
\text { H. pylori positive } \\
\text { group- } 82.5 \% .\end{array}$ \\
\hline 25 & Song et al. [70] & 2000 & $\begin{array}{l}\text { PCR-860-bp } \\
\text { fragment }\end{array}$ & 21 patients & $\begin{array}{l}\text { Overall- } 47.6 \% \text {; among } \\
\text { H. pylori positive } \\
\text { group- } 100 \%\end{array}$ \\
\hline 26 & $\begin{array}{l}\text { Qureshi et al. } \\
\qquad[50]\end{array}$ & 1999 & CLO test & 60 dyspeptic patients & $\begin{array}{l}\text { Overall } 33.3 \% \text {; in } H . \\
\text { pylori positive } 55.6 \%\end{array}$ \\
\hline 27 & $\begin{array}{c}\text { Oshowo et al. } \\
\text { [32] }\end{array}$ & 1998 & $\begin{array}{l}\text { PCR-16S rRNA } \\
\text { and culture }\end{array}$ & $\begin{array}{l}208 \text { dyspeptic patients-116 } \\
\mathrm{H} \text {. pylori positive and } 92 \mathrm{H} \text {. } \\
\text { pylori negative }\end{array}$ & $\begin{array}{l}\text { By PCR-Overall 6.25\%; } \\
\text { in H. pylori } \\
\text { positive-11.2\% } \\
\text { By culture-Overall } 1 \% \text {; in } \\
\text { H. pylori positive-1.7\% } \\
\text { By both } \\
\text { methods-Overall } 7.2 \% \text { in } \\
\text { H. pylori positive-12.9\%. }\end{array}$ \\
\hline 28 & $\begin{array}{c}\text { Hardo et al. } \\
\text { [24] }\end{array}$ & 1995 & 16S rRNA & 62 dyspeptic patients & 0 \\
\hline 29 & $\begin{array}{c}\text { Mapstone et al. } \\
{[72]}\end{array}$ & 1993 & PCR-16S rRNA & $\begin{array}{l}21 \text { dyspeptic patients-13 } \\
\text { with } H \text {. pylori associated } \\
\text { gastritis and } 8 \text { who had } \\
\text { normal histology }\end{array}$ & $\begin{array}{c}15.4 \% \text { in gastritis } \\
\text { group-overall prevalence } \\
9.5 \%\end{array}$ \\
\hline 30 & $\begin{array}{l}\text { Nguyen et al. } \\
{[73]}\end{array}$ & 1993 & PCR-16S rRNA & 25 dyspeptic patients & $\begin{array}{c}\text { Overall } 28 \% \text {, among } H \text {. } \\
\text { pylori positive } \\
\text { individuals } 38.8 \%\end{array}$ \\
\hline 31 & $\begin{array}{l}\text { Krajden et al. } \\
\qquad[16]\end{array}$ & 1989 & Culture & $\begin{array}{l}71 \text { patients undergoing } \\
\text { endoscopy }\end{array}$ & $\begin{array}{c}1.4 \% \text { of the total } \\
\text { population and } 3.5 \% \text { of } \\
\text { H. pylori positive } \\
\text { subjects }\end{array}$ \\
\hline
\end{tabular}

had H. pylori in dental plaque harbored Bacteroides forsythus in their oral cavities. Based on the previously mentioned findings, the authors concluded that close attention should be given to periodontitis patients who harbor $H$. pylori in the oral cavity.
Association between periodontal disease and $H$. pylori infection was tested in a case-control study among 134 dyspeptic patients reporting for upper gastrointestinal endoscopy [38]. The periodontal status of the patients was examined as a dichotomous variable with patients being 
TABLE 6: Data regarding the association between periodontal diseases and H. pylori infection.

\begin{tabular}{|c|c|c|c|c|c|c|}
\hline No. & Authors & Year & $\begin{array}{l}\text { Definition of gingi- } \\
\text { val/periodontal } \\
\text { disease }\end{array}$ & Sample size & $\begin{array}{l}\text { Association with } \\
\text { oral } H \text {. pylori }\end{array}$ & $\begin{array}{l}\text { Association with } \\
\text { gastric } H \text {. pylori }\end{array}$ \\
\hline 1 & $\begin{array}{l}\text { Silva et al. } \\
\quad[58]\end{array}$ & 2010 & $\begin{array}{c}\text { At least } 4 \text { teeth } \\
\text { with } P D \geq 5 \mathrm{~mm} \\
\text { and } C A L>3 \mathrm{~mm}\end{array}$ & 115 dyspeptic patients & Significant & Not evaluated \\
\hline 2 & $\begin{array}{l}\text { Namiot et al. } \\
{[26]}\end{array}$ & 2010 & $\begin{array}{l}\text { Russell's } \\
\text { periodontal index }\end{array}$ & 155 dyspeptic patients & Nonsignificant & Not evaluated \\
\hline 3 & $\begin{array}{l}\text { Gonçalves et } \\
\text { al. [60] }\end{array}$ & 2009 & $\begin{array}{l}\text { At least } 3 \text { sites with } \\
\mathrm{PD} \geq 5 \mathrm{~mm} \text { and/or } \\
\mathrm{CAL} \geq 4 \mathrm{~mm} \text { and } \\
\text { BOP }\end{array}$ & $\begin{array}{l}23 \text { HIV seropositive } \\
\text { patients of whom } 13 \text { had } \\
\text { periodontitis and } 10 \text { were } \\
\text { periodontally healthy; } 31 \\
\text { HIV seronegative patients } \\
\text { of } 17 \text { had periodontitis and } \\
14 \text { were periodontally } \\
\text { healthy }\end{array}$ & Significant & \\
\hline 4 & $\begin{array}{l}\text { Al Asqah et } \\
\text { al. [35] }\end{array}$ & 2009 & $\begin{array}{l}\mathrm{BOP}+\mathrm{PD} \geq 3 \mathrm{~mm} \\
\text { on at least } 4 \text { teeth }\end{array}$ & $\begin{array}{l}\text { Dyspeptic patients- } 62 \\
\text { patients with periodontitis } \\
\text { and } 39 \text { without } \\
\text { periodontitis }\end{array}$ & Significant & Significant \\
\hline 5 & Liu et al. [61] & 2009 & Gingival index & 443 dyspeptic patients & Significant & Not evaluated \\
\hline 6 & $\begin{array}{l}\text { Zaric et al. } \\
\quad[40]\end{array}$ & 2009 & $\begin{array}{l}\text { Mean PD, CAL, } \\
\text { and gingival index } \\
\text { scores }\end{array}$ & $\begin{array}{l}66 \text { dyspeptic patients with } \\
H \text {. pylori infection of } \\
\text { gastric mucosa }\end{array}$ & $\begin{array}{l}\text { Significant for } \\
\text { mean PD and CAL; } \\
\text { not significant for } \\
\text { gingival index } \\
\text { scores }\end{array}$ & Not evaluated \\
\hline 7 & $\begin{array}{c}\text { Bürgers et al. } \\
{[36]}\end{array}$ & 2008 & $\begin{array}{c}\text { Periodontal } \\
\text { Screening Index }\end{array}$ & 94 dyspeptic patients & Nonsignificant & Nonsignificant \\
\hline 8 & $\begin{array}{l}\text { Namiot et al. } \\
{[77]}\end{array}$ & 2007 & $\begin{array}{l}\text { Russell's } \\
\text { periodontal index }\end{array}$ & $\begin{array}{l}137 \mathrm{H} \text {. pylori positive } \\
\text { patients with peptic ulcer }\end{array}$ & $\begin{array}{l}\text { Outcome variable } \\
\text { was efficacy of HP } \\
\text { eradication }\end{array}$ & $\begin{array}{c}\text { Nonsignificant } \\
\text { (outcome variable } \\
\text { was efficacy of } H \text {. } \\
\text { pylori eradication) }\end{array}$ \\
\hline 9 & $\begin{array}{l}\text { Anand et al. } \\
{[38]}\end{array}$ & 2006 & $\begin{array}{l}\text { Patients with one } \\
\text { or more sites with a } \\
\mathrm{PD} \geq 3 \mathrm{~mm} \text { and } \\
\text { CAL } \geq 3 \mathrm{~mm} \text { at the } \\
\text { same site }\end{array}$ & $\begin{array}{l}\text { Sixty-five dyspeptic patients } \\
\text { with } H \text {. pylori infection and } \\
69 \text { dyspeptic patients } \\
\text { without } H \text {. pylori infection }\end{array}$ & Not evaluated & Nonsignificant \\
\hline 10 & $\begin{array}{c}\text { Gebara et al. } \\
{[66]}\end{array}$ & 2004 & $\begin{array}{c}\text { Gingivitis } \\
\text { group-patients } \\
\text { with } \mathrm{PD} \leq 3 \mathrm{~mm} \\
\text { and } \mathrm{BOP} \text { on at } \\
\text { least } 4 \text { sites; } \\
\text { periodontitis } \\
\text { group-BOP }+\mathrm{PD} \geq \\
5 \mathrm{~mm} \text { on at least } 4 \\
\text { teeth }\end{array}$ & $\begin{array}{l}15 \text { gingivitis and } 15 \\
\text { periodontitis patients-All } \\
\text { were } H \text {. pylori positive in } \\
\text { antral mucosa }\end{array}$ & Nonsignificant & \\
\hline 11 & $\begin{array}{l}\text { Umeda et al. } \\
\text { [37] }\end{array}$ & 2003 & $\begin{array}{c}\text { Presence of } \\
\text { periodontal } \\
\text { pockets } \geq 4 \mathrm{~mm}\end{array}$ & $\begin{array}{l}28 \text { patients who harbored } \\
H . \text { pylori in } \\
\text { stomach/duodenum }\end{array}$ & Significant & Not evaluated \\
\hline 12 & $\begin{array}{l}\text { Choudhury } \\
\text { et al. [22] }\end{array}$ & 2003 & CPI & 124 dyspeptic patients & Significant & Not evaluated \\
\hline 13 & Dye et al. [34] & 2002 & $\begin{array}{c}\text { Presence of } 1 \\
\text { dental site with PD } \\
\quad \geq 5 \mathrm{~mm}\end{array}$ & $\begin{array}{l}\text { Data from } 4504 \\
\text { participants of NHANES } \\
\text { III Survey }\end{array}$ & Not evaluated & Significant \\
\hline 14 & $\begin{array}{l}\text { Berroteran et } \\
\text { al. [39] }\end{array}$ & 2002 & $\begin{array}{c}\text { Gingival } \\
\text { index-scoring 0-3 }\end{array}$ & $\begin{array}{l}32 \text { dyspeptic patients and } \\
20 \text { asymptomatic controls }\end{array}$ & Nonsignificant & Nonsignificant \\
\hline
\end{tabular}


TABLE 6: Continued.

\begin{tabular}{|c|c|c|c|c|c|c|}
\hline No. & Authors & Year & $\begin{array}{l}\text { Definition of gingi- } \\
\text { val/periodontal } \\
\text { disease }\end{array}$ & Sample size & $\begin{array}{c}\text { Association with } \\
\text { oral } H \text {. pylori }\end{array}$ & $\begin{array}{l}\text { Association with } \\
\text { gastric } H \text {. pylori }\end{array}$ \\
\hline 15 & $\begin{array}{c}\text { Dowsett et al. } \\
{[18]}\end{array}$ & 1999 & $\begin{array}{l}\text { Full mouth } \\
\text { periodontal } \\
\text { examination }\end{array}$ & 242 subjects & Nonsignificant & Nonsignificant \\
\hline 16 & $\begin{array}{l}\text { Savoldi et al. } \\
\text { [29] }\end{array}$ & 1998 & Gingival index & 80 dyspeptic patients & $\begin{array}{l}\text { Nonsignificant- } \\
\text { None of the plaque } \\
\text { samples were } \\
\text { positive for HP }\end{array}$ & Nonsignificant \\
\hline 17 & $\begin{array}{l}\text { Hardo et al. } \\
\qquad[24]\end{array}$ & 1995 & CPITN & 62 dyspeptic patients & Nonsignificant & Nonsignificant \\
\hline 18 & $\begin{array}{c}\text { Nguyen et al. } \\
{[73]}\end{array}$ & 1993 & Gingival index & 25 dyspeptic patients & Nonsignificant & Nonsignificant \\
\hline
\end{tabular}

described as being either diseased or healthy depending on their periodontal status. Among the cases, 30 subjects out of $65(46.2 \%)$ had periodontal disease compared to only 20 out of $69(29 \%)$ in comparison to the controls. Although the univariate analysis suggested that the relationship was significant, when analyzed by logistic regression, the difference was found to be not significant.

Lack of association between $H$. pylori infection and periodontal disease was reported by Berroteran et al. [39] based on the results from their study of a Venezuelan population. Gingival and Plaque indices were used to assess the gingival and oral hygiene status of the 32 dyspeptic patients and 20 asymptomatic subjects. It was found that patients with poor oral hygiene and periodontal status had a similar prevalence of $H$. pylori to patients with good-tomoderate dental hygiene.

To elucidate the possible sources of $H$. pylori infection in an isolated, rural population in Guatemala, Dowsett et al. [18] examined 242 subjects in family units. Periodontal status, $H$. pylori antibody status, and presence of $H$. pylori in the dental plaque, dorsum of tongue, and fingernails were recorded. PCR based on $16 \mathrm{~S}$ rRNA gene of $H$. pylori were employed for the detection of the microorganism in the plaque, tongue, and finger nail samples. It was found that there was no statistically significant relationship between H. pylori status and periodontal disease. A high rate of oral carriage was found irrespective of periodontal status, showing no association with pocket depth.

Al Asqah et al. [35] reported that 60\% (37/62) of the periodontitis patients in their study harbored $H$. pylori in their stomach compared to only $33 \%(13 / 39)$ of the patients without periodontitis. Furthermore, they reported that the prevalence of $H$. pylori in the dental plaque was higher among periodontitis patients $(79 \%, 49 / 62)$ than in patients without periodontitis $(43 \%, 17 / 39)$. They also reported that the presence of the bacterium in both locations was higher among periodontitis patients $(46.8 \%, 29 / 62)$ than in patients without periodontitis $(10.3 \%, 4 / 39)$.

2.12. Effects of Systemic Anti-H. pylori Therapy on Dental Plaque. A total of 8 studies [30, 40-46] were reviewed in which the effect of anti-H. pylori therapy on its presence in the dental plaque was evaluated. The summary of these studies are given in Table 7. In 6 of these 8 studies, PCR was used to detect $H$. pylori in dental plaque while in one study [30] urease test was used and in the other [46] smear cytology was used. In their study on $82 \mathrm{H}$. pylori positive patients, Butt et al. [46] treated 27 of these patients with anti-H. pylori therapy (triple therapy- 2 antibiotics and 1 proton pump inhibitor) alone and reported $100 \%$ prevalence of $H$. pylori in the dental plaque of these 27 patients after 10 days of treatment. Gürbüz et al. [30] conducted a study among 75 dyspeptic patients in which $H$. pylori positive patients were treated with antiH. pylori therapy. In this study, initially 68 (91\%) patients were positive for $H$. pylori in dental plaque and $65(87 \%)$ were positive for $H$. pylori in the gastric mucosa. When the procedures were repeated after 1 month following treatment, the authors reported that all the dental plaque samples were positive for $H$. pylori although they had not mentioned the number of patients treated with anti-H. pylori therapy. Among the studies in which PCR was employed for pathogen detection, Gao et al. [44] reported that, among $37 \mathrm{H}$. pylori positive patients, the prevalence of plaque colonization was $29.7 \%$ and $43.2 \%$, respectively, at 4 weeks and 1 year after anti-H. pylori therapy. Gebara et al. [42], in their study on 30 dental patients with periodontitis and $H$. pylori infection, reported an increase in the prevalence of plaque colonization from $20 \%$ to $30 \%$ in supragingival plaque and from $26.6 \%$ to $46.7 \%$ in subgingival plaque. Suk et al. [45] reported that, after anti- $H$. pylori therapy, the microorganism persisted in the dental plaque of $92.9 \%(n=26)$ of the 28 patients who harbored the organism in the dental plaque before anti- $H$. pylori therapy. Zaric et al. [40] reported that, after anti- $H$. pylori therapy, the pathogen could be detected in the dental plaque of $66.7 \%(n=14)$ of the 21 patients who were positive for the microorganism both in the subgingival plaque and gastric mucosa before the intervention. Miyabayashi et al. [43] in their study on 47 dyspeptic patients reported $48.9 \%$ $(n=23)$ positive for oral $H$. pylori and $38.3 \%(n=18)$ had $H$. pylori in plaque before anti-H. pylori treatment. At 4 weeks after treatment, they reported that $31.9 \%$ of the patients were positive for oral $H$. pylori. However, they did not specify 
TABLE 7: Data regarding effects of anti-H. pylori therapy on dental plaque.

\begin{tabular}{|c|c|c|c|c|c|c|c|}
\hline No. & Authors & Year & $\begin{array}{l}\text { Method used } \\
\text { to detect } H . \\
\text { pylori }\end{array}$ & Sample size & $\begin{array}{c}\text { Prevalence of } \\
\text { H. pylori }\end{array}$ & $\begin{array}{c}\text { Prevalence after } \\
\text { anti-H. pylori } \\
\text { therapy }\end{array}$ & $\begin{array}{l}\text { Effect on } H . \\
\text { pylori infection }\end{array}$ \\
\hline 1 & $\begin{array}{l}\text { Gao et al. } \\
\quad[44]\end{array}$ & 2011 & $\begin{array}{l}\text { PCR-ureC } \\
\text { and cagA } \\
\text { genes }\end{array}$ & $\begin{array}{l}80 \text { patients with } H . \text { pylori } \\
\text { infection- } 37 \text { treated with } \\
\text { anti- } H \text {. pylori therapy } \\
\text { and } 43 \text { treated with } \\
\text { anti- } H \text {. pylori therapy } \\
\text { and periodontal therapy }\end{array}$ & & $\begin{array}{c}\text { After } 4 \\
\text { weeks- } 29.7 \% \text { in } \\
\text { gp A and } 4.7 \% \\
\text { in gp B; after } 1 \\
\text { year- } 43.2 \% \text { in gp } \\
\text { A and } 18.6 \% \text { in } \\
\text { gp B }\end{array}$ & $\begin{array}{c}\text { Eradication rate } \\
\text { of gastric } H . \\
\text { pylori. After } 4 \\
\text { weeks-73\% in gp } \\
\text { A and } 81.4 \% \text { in } \\
\text { gp B } \\
\text { After } 1 \\
\text { year-32.4\% in gp } \\
\text { A and } 62.8 \% \text { in } \\
\text { gp B }\end{array}$ \\
\hline 2 & $\begin{array}{l}\text { Bago et al. } \\
\quad[41]\end{array}$ & 2011 & $\begin{array}{l}\text { PCR-16S } \\
\text { rDNA }\end{array}$ & $\begin{array}{l}56 \text { patients with chronic } \\
\text { periodontitis and gastric } \\
\text { H. pylori positive }\end{array}$ & $\begin{array}{c}37.5 \% \\
(n=21)\end{array}$ & 0 & $\begin{array}{c}\text { Eradication rate } \\
\text { in stomach was } \\
76.2 \%\end{array}$ \\
\hline 3 & $\begin{array}{l}\text { Zaric et al. } \\
\quad[40]\end{array}$ & 2009 & PCR & $\begin{array}{l}44 \text { patients: } 21 \text { patients } \\
\text { positive for } H \text {. pylori in } \\
\text { subgingival dental } \\
\text { plaque and gastric } \\
\text { mucosa and } 23 \text { patients } \\
\text { who were positive for } H \text {. } \\
\text { pylori only in gastric } \\
\text { mucosa-all } 44 \text { received } \\
\text { only for } H \text {. pylori (triple) } \\
\text { therapy }\end{array}$ & & In $\mathrm{G}^{+} \mathrm{O}^{+} \mathrm{t}-66.7 \%$ & $\begin{array}{c}\text { In the } \mathrm{G}^{+} \mathrm{O}^{+} \mathrm{t} \\
\text { group, only } \\
47.6 \% \\
\text { showed } \\
\text { eradication of } \\
\text { gastric } H \text {. pylori } \\
\text { compared to } \\
87.4 \% \text { in } \mathrm{G}^{+} \mathrm{O}^{-} \mathrm{t}\end{array}$ \\
\hline 4 & $\begin{array}{c}\text { Gebara et al. } \\
{[42]}\end{array}$ & 2006 & $\begin{array}{l}\text { PCR-16S } \\
\text { rDNA }\end{array}$ & $\begin{array}{l}30 \text { dentate patients with } \\
\text { gingivitis/periodontitis } \\
\text { and } H \text {. pylori infection } \\
\text { who received anti- } H \text {. } \\
\text { pylori therapy }\end{array}$ & $\begin{array}{c}20 \%(n=6) \\
\text { in supra- } \\
\text { gingival } \\
\text { plaque and } \\
26.6 \%(n=8) \\
\text { in } \\
\text { sub-gingival } \\
\text { plaque }\end{array}$ & $\begin{array}{c}30 \% \text { in } \\
\text { supra-gingival } \\
\text { plaque and } \\
46.7 \% \text { in } \\
\text { sub-gingival } \\
\text { plaque }\end{array}$ & \\
\hline 5 & $\begin{array}{l}\text { Gürbüz et al. } \\
{[30]}\end{array}$ & 2003 & CLO test & $\begin{array}{l}75 \text { dyspeptic patients of } \\
\text { which } 61 \text { were } H \text {. pylori } \\
\text { positive and also had } H \text {. } \\
\text { pylori in dental plaque }\end{array}$ & $\begin{array}{c}90.7 \% \\
(n=68) \\
81.3 \% \\
(n=61) \text { had } \\
\text { co-infection }\end{array}$ & $100 \%$ & \\
\hline 6 & Suk et al. [45] & 2002 & PCR-cagA & $\begin{array}{l}\text { Sixty-five patients with } \\
\text { dyspeptic symptoms }\end{array}$ & $\begin{array}{c}\text { Overall- } \\
43.1 \% \\
(n=28) \\
73.7 \%(28 / 38) \\
\text { among } H . \\
\text { pylori } \\
\text { positive } \\
\text { patients }\end{array}$ & $92.9 \%$ & \\
\hline 7 & $\begin{array}{l}\text { Butt et al. } \\
\quad[46]\end{array}$ & 2001 & $\begin{array}{l}\text { Smear } \\
\text { cytology }\end{array}$ & $\begin{array}{l}82 \text { patients positive for } \\
\text { H. pylori in dental } \\
\text { plaque: } 27 \text { received only } \\
\text { anti-H. pylori therapy } \\
\text { (gp 1); } 25 \text { received } \\
\text { anti-HP therapy + } \\
\text { periodontal therapy (gp } \\
\text { 2); } 30 \text { received only } \\
\text { periodontal therapy (gp } \\
\text { 3) }\end{array}$ & $100 \%$ & $\begin{array}{l}100 \% \text { in gp } 1 ; \\
16 \% \text { in gp } 2 ; 10 \% \\
\text { in gp } 3\end{array}$ & \\
\hline
\end{tabular}


TABLe 7: Continued.

\begin{tabular}{|c|c|c|c|c|c|c|c|}
\hline No. & Authors & Year & $\begin{array}{c}\text { Method used } \\
\text { to detect } H \text {. } \\
\text { pylori }\end{array}$ & Sample size & $\begin{array}{c}\text { Prevalence of } \\
\text { H. pylori }\end{array}$ & $\begin{array}{c}\text { Prevalence after } \\
\text { anti-H. pylori } \\
\text { therapy }\end{array}$ & $\begin{array}{c}\text { Effect on } H \text {. } \\
\text { pylori infection }\end{array}$ \\
\hline 8 & $\begin{array}{c}\text { Miyabayashi } \\
\text { et al. [43] }\end{array}$ & 2000 & PCR-ureA & $\begin{array}{l}47 \text { patients with chronic } \\
\text { gastritis or peptic } \\
\text { ulcer- } 48.9 \%(n=23) \\
\text { were positive for oral HP } \\
\text { and } 38.3 \%(n=18) \text { had } \\
\text { HP in plaque }\end{array}$ & & $\begin{array}{l}\text { Oral prevalence } \\
\text { at } 4 \text { weeks-31.9 }\end{array}$ & $\begin{array}{c}\text { At } 4 \\
\text { weeks-91.6\% of } \\
\text { subjects } \\
\text { negative for oral } \\
\text { H. pylori were } \\
\text { successfully } \\
\text { eradicated of } \\
\text { HP infection } \\
\text { compared to } \\
52.2 \% \text { in oral } H \text {. } \\
\text { pylori positive } \\
\text { patients. At } 2 \\
\text { years-95.8\% of } \\
\text { subjects } \\
\text { negative for oral } \\
\text { H. pylori were } \\
\text { successfully } \\
\text { eradicated of } H \text {. } \\
\text { pylori infection } \\
\text { compared to } \\
\text { 69.5\% in oral } H \text {. } \\
\text { pylori positive } \\
\text { patients }\end{array}$ \\
\hline
\end{tabular}

how many patients were positive for the microorganism in the dental plaque. Contrary to these studies, Bago et al. [41], reported that 21 patients were positive for $H$. pylori in the dental plaque in a study on 56 chronic periodontitis patients who harbored $H$. pylori in the gastric mucosa. They reported complete eradication of $H$. pylori from dental plaque in all of the 21 patients following anti-H. pylori therapy consisting of 2 antibiotic and 1 proton pump inhibitor (PPI).

2.13. Effects of Periodontal Therapy on Dental PlaqueAssociated H. pylori. Three studies have evaluated the effects of nonsurgical periodontal therapy on $H$. pylori residing in the dental plaque (Table 8). Butt et al. [46] categorized 82 patients who harbored $H$. pylori in their dental plaque into 3 groups based on the type of intervention-Group 1 which received only anti- $H$. pylori therapy $(n=27)$, Group 2 which received anti- $H$. pylori therapy plus periodontal therapy $(n=$ 25 ), and Group 3 which received only periodontal therapy $(n=30)$. Ten days after treatment, the prevalence of $H$. pylori in dental plaque for Groups 1, 2, and 3 were $100 \%$, $16 \%$, and $10 \%$, respectively. In a study on 43 patients who harbored $H$. pylori both in the subgingival plaque and gastric mucosa, Zaric et al. [40] reported that, among 22 patients who received both anti- $H$. pylori therapy and periodontal therapy, $H$. pylori was detected in the dental plaque of only 6 patients 3 months after completion of treatment compared to 21 patients who received only anti-H. pylori therapy among whom the prevalence after intervention was $66.7 \%$. Gao et al. [44], in their study to evaluate the effects of combination of anti-H. pylori therapy (triple therapy) and periodontal therapy for the management of $H$. pylori infection, treated 37 patients with anti-H. pylori therapy alone and 43 patients with a combination of anti-H. pylori therapy and periodontal therapy. The detection rates of $H$. pylori in the dental plaque for both groups at 4 weeks after intervention were $29.7 \%$ and $4.7 \%$, respectively, and $43.2 \%$ and $18.6 \%$, respectively, one year after intervention.

2.14. Effects of Periodontal Therapy on Gastric H. pylori Infection. Three studies have evaluated the effects of periodontal therapy on gastric $H$. pylori infection. Gao et al. [44] reported that, among $43 \mathrm{H}$. pylori positive patients who received both anti-H. pylori therapy and periodontal therapy, the gastric eradication rate at 4 weeks and 1 year after intervention was $81.4 \%$ and $62.8 \%$, respectively, while the eradication rates at same time periods among $37 \mathrm{H}$. pylori positive patients who received only anti- $H$. pylori therapy were $73 \%$ and $32.4 \%$. Zaric et al. [40] conducted a study among 43 patients who were positive for $H$. pylori in both subgingival plaque and gastric mucosa in which 21 patients received only anti- $H$. pylori therapy while 22 received anti- $H$. pylori therapy along with periodontal therapy. Three months after completion of treatment, $77.3 \%$ of the patients who received both anti- $H$. pylori therapy and periodontal therapy showed gastric eradication compared to only $47.6 \%$ of the patients who received only anti-H. pylori therapy. The authors also reported that eradication in the stomach coincided with eradication from the oral cavity; that is, all 16 of the individuals who received both forms of therapy and showed eradication of oral $H$. pylori, also showed eradication of gastric $H$. pylori. Five of the 
TABLE 8: Data regarding effects of periodontal therapy on $H$. pylori in dental plaque and gastric infection.

\begin{tabular}{|c|c|c|c|c|c|c|c|}
\hline No. & Authors & Year & $\begin{array}{l}\text { Method used } \\
\text { to detect } H \text {. } \\
\text { pylori }\end{array}$ & Sample size & $\begin{array}{c}\text { Prevalence of } H . \\
\text { pylori }\end{array}$ & $\begin{array}{c}\text { Prevalence after } \\
\text { anti-H. pylori } \\
\text { therapy }\end{array}$ & $\begin{array}{l}\text { Effect on } H . \text { pylori } \\
\text { infection }\end{array}$ \\
\hline 1 & $\begin{array}{l}\text { Gao et al. } \\
\quad[44]\end{array}$ & 2011 & $\begin{array}{l}\text { PCR-ureC } \\
\text { and cagA } \\
\text { genes }\end{array}$ & $\begin{array}{l}80 \text { patients with } H \text {. } \\
\text { pylori infection- } 37 \\
\text { treated with anti-HP } \\
\text { therapy (gp A) and } 43 \\
\text { treated with anti- } H \text {. } \\
\text { pylori therapy and } \\
\text { periodontal therapy } \\
\text { (gp B) }\end{array}$ & & $\begin{array}{c}\text { After } 4 \\
\text { weeks- } 29.7 \% \text { in gp } \\
\text { A and } 4.7 \% \text { in gp } \\
\text { B; after } 1 \\
\text { year- } 43.2 \% \text { in gp A } \\
\text { and } 18.6 \% \text { in gp B }\end{array}$ & $\begin{array}{l}\text { Eradication rate of } \\
\text { gastric } H \text {. pylori. } \\
\text { After } 4 \text { weeks- } 73 \% \\
\text { in gp A and } 81.4 \% \\
\text { in gp B, After } 1 \\
\text { year-32.4\% in gp A } \\
\text { and } 62.8 \% \text { in gp B }\end{array}$ \\
\hline 2 & $\begin{array}{l}\text { Zaric et al. } \\
\quad[40]\end{array}$ & 2009 & PCR & $\begin{array}{l}43 \text { patients positive } \\
\text { for } H \text {. pylori in sub } \\
\text { gingival dental plaque } \\
\text { and gastric mucosa: } 21 \\
\text { received only anti- } H \text {. } \\
\text { pylori triple therapy } \\
\left(\mathrm{G}^{+} \mathrm{O}^{+} \mathrm{t}\right) ; 22 \text { received } \\
\text { anti- } H \text {. pylori triple } \\
\text { therapy }+ \text { periodontal } \\
\text { therapy }\left(\mathrm{G}^{+} \mathrm{O}^{+} \text {tp) }\right.\end{array}$ & & $\begin{array}{l}\text { In } \mathrm{G}^{+} \mathrm{O}^{+} \mathrm{t}-66.7 \% \\
\text { in } \mathrm{G}^{+} \mathrm{O}^{+} \text {tp- }-27.3 \%\end{array}$ & $\begin{array}{l}\text { In the } \mathrm{G}^{+} \mathrm{O}^{+} \text {tp } \\
\text { group, } 77.3 \% \\
\text { showed eradication } \\
\text { of gastric } H \text {. pylori } \\
\text { compared to } 47.6 \% \\
\text { in } \mathrm{G}^{+} \mathrm{O}^{+} \text {t. } H \text {. pylori } \\
\text { eradication in the } \\
\text { stomach and the } \\
\text { oral cavity } \\
\text { coincided-that is, } \\
\text { all } 16 \text { of the } \\
\text { individuals } \\
\text { negative for oral } H \text {. } \\
\text { pylori were also } \\
\text { negative for gastric } \\
\text { H. pylori. Five of } \\
\text { the participants } \\
\text { positive for oral } \\
\text { samples were } \\
\text { positive for gastric } \\
\text { H. pylori as well. }\end{array}$ \\
\hline 3 & Jia et al. [47] & 2009 & & $\begin{array}{l}107 \text { dyspeptic } \\
\text { patients-56 received } \\
\text { dental plaque control } \\
\text { (test) and } 51 \text { did not } \\
\text { (control) }\end{array}$ & & & $\begin{array}{l}\text { Prevalence of } H . \\
\text { pylori in gastric } \\
\text { mucosa was } 19.64 \% \\
\text { in test group and } \\
84.31 \% \text { in control } \\
\text { group }\end{array}$ \\
\hline 4 & $\begin{array}{l}\text { Butt et al. } \\
\quad[46]\end{array}$ & 2001 & $\begin{array}{l}\text { Smear } \\
\text { cytology }\end{array}$ & $\begin{array}{l}82 \text { patients positive } \\
\text { for } H \text {. pylori in dental } \\
\text { plaque: } 27 \text { received } \\
\text { only anti-H. pylori } \\
\text { therapy (gp 1); } 25 \\
\text { received anti- } H \text {. pylori } \\
\text { therapy + periodontal } \\
\text { therapy (gp 2); } 30 \\
\text { received only } \\
\text { periodontal therapy } \\
\text { (gp 3) }\end{array}$ & $100 \%$ & $\begin{array}{c}100 \% \text { in gp } 1 ; 16 \% \\
\text { in gp } 2 ; 10 \% \text { in gp } 3\end{array}$ & \\
\hline
\end{tabular}

participants in this group who were positive for oral samples were positive for gastric $H$. pylori as well. Jia et al. [47], in a study on $107 \mathrm{H}$. pylori positive dyspeptic patient, reported that, 6 months after complete eradication of $H$. pylori from gastric mucosa, reinfection of the gastric mucosa by the bacterium was observed in $84.31 \%$ of the patients who did not receive any form of dental plaque control compared to only
$19.64 \%$ of the patients who received dental plaque control and full-mouth scaling and root planing.

\section{Conclusion}

H. pylori is a major etiologic factor in the development of gastritis and peptic ulcer disease. There is sufficient evidence 
on the presence of $H$. pylori in the subgingival oral biofilm which could act as a reservoir for harboring $H$. pylori, leading to gastric reinfection. Hence, it is imperative to adapt a multidisciplinary clinical management protocol, merging the triple therapy to periodontal mechanical treatment and chemical antiseptic disinfection. Further research that may be directed towards controlled randomized clinical trials are necessary for testing the efficacy of the multidisciplinary therapeutic regimen.

\section{Conflict of Interests}

The authors declare that there is no conflict of interests regarding the publication of this paper.

\section{References}

[1] M. J. Blaser, "Ecology of Helicobacter pylori in the human stomach," Journal of Clinical Investigation, vol. 100, no. 4, pp. 759-762, 1997.

[2] J. Warren and B. Marshall, "Unidentified curved bacilli on gastric epithelium in active chronic gastritis," The Lancet, vol. 1, pp. 1273-1275, 1983.

[3] B. E. Dunn, H. Cohen, and M. J. Blaser, "Helicobacter pylori," Clinical Microbiology Reviews, vol. 10, no. 4, pp. 720-741, 1997.

[4] R. Wang, T. Wang, K. Chen et al., "Helicobacter pylori infection and gastric cancer: evidence from a retrospective cohort study and nested case-control study in China," World Journal of Gastroenterology, vol. 8, no. 6, pp. 1103-1107, 2002.

[5] "Schistosomes, liver flukes and Helicobacter pylori. IARC Working Group on the Evaluation of Carcinogenic Risks to Humans. Lyon, 7-14 June 1994," IARC Monographs on the Evaluation of Carcinogenic Risks to Humans, vol. 61, pp. 1-241, 1994.

[6] X. H. Qu, X. L. Huang, P. Xiong et al., "Does Helicobacter pylori infection play a role in iron deficiency anemia? A metaanalysis," World Journal of Gastroenterology, vol. 16, no. 7, pp. 886-896, 2010.

[7] E. Jia, F. Zhao, B. Hao et al., "Helicobacter pylori infection is associated with decreased serum levels of high density lipoprotein, but not with the severity of coronary atherosclerosis," Lipids in Health and Disease, vol. 8, p. 59, 2009.

[8] B. Farsak, A. Yildirir, Y. Akyön et al., "Detection of chlamydia pneumoniae and Helicobacter pylori DNA in human atherosclerotic plaques by PCR," Journal of Clinical Microbiology, vol. 38, no. 12, pp. 4408-4411, 2000.

[9] R. Allaker, K. Young, J. Hardie, P. Domizio, and N. J. Meadows, "Prevalence of Helicobacter pylori at oral and gastrointestinal sites in children: evidence for possible oral-to-oral transmission," Journal of Medical Microbiology, vol. 51, no. 4, pp. 312-317, 2002.

[10] E. Moreira Jr., R. Santos, V. Nassri et al., "Risk factors for Helicobacter pylori infection in children: is education a main determinant?" Epidemiology and Infection, vol. 132, no. 2, pp. 327-335, 2004.

[11] L. M. Pérez, F. Codony, D. L. Leyton, M. Fittipaldi, B. Adrados, and J. Morató, "Quantification of Helicobacter pylori levels in soil samples from public playgrounds in Spain," Journal of Zhejiang University B, vol. 11, no. 1, pp. 27-29, 2010.

[12] A. Dubois, N. Fiala, L. M. Heman-Ackah et al., "Natural gastric infection with Helicobacter pylori in monkeys: a model for spiral bacteria infection in humans," Gastroenterology, vol. 106, no. 6, pp. 1405-1417, 1994.

[13] J. G. Fox, M. Batchelder, R. Marini et al., "Helicobacter pyloriinduced gastritis in the domestic cat," Infection and Immunity, vol. 63, no. 7, pp. 2674-2681, 1995.

[14] W. Prachasilpchai, S. Nuanualsuwan, T. Chatsuwan, S. Techangamsuwan, S. Wangnaitham, and A. Sailasuta, "Diagnosis of Helicobacter spp. infection in canine stomach," Journal of Veterinary Science, vol. 8, no. 2, pp. 139-145, 2007.

[15] C. Hwang, H. Han, and H. Youn, "Prevalence and clinical characterization of gastric Helicobacter species infection of dogs and cats in Korea," Journal of Veterinary Science, vol. 3, no. 2, pp. 123-133, 2002.

[16] S. Krajden, M. Fuksa, J. Anderson et al., "Examination of human stomach biopsies, saliva, and dental plaque for Campylobacter pylori," Journal of Clinical Microbiology, vol. 27, no. 6, pp. 13971398, 1989.

[17] P. Majmudar, S. M. Shah, K. R. Dhunjibhoy, and H. G. Desai, "Isolation of Helicobacter pylori from dental plaques in healthy volunteers," Indian Journal of Gastroenterology, vol. 9, no. 4, pp. 271-272, 1990.

[18] S. A. Dowsett, L. Archila, V. A. Segreto et al., "Helicobacter pylori infection in indigenous families of Central America: serostatus and oral and fingernail carriage," Journal of Clinical Microbiology, vol. 37, no. 8, pp. 2456-2460, 1999.

[19] S. Patchett, S. Beattie, E. Leen, C. Keane, and C. O’Morain, "Helicobacter pylori and duodenal ulcer recurrence," American Journal of Gastroenterology, vol. 87, no. 1, pp. 24-27, 1992.

[20] H. Desai, H. Gill, K. Shankaran, P. Mehta, and S. R. Prabhu, "Dental plaque: a permanent reservoir of Helicobacter pylori?" Scandinavian Journal of Gastroenterology, vol. 26, no. 11, pp. 1205-1208, 1991.

[21] N. Avcu, F. Avcu, C. Beyan et al., "The relationship between gastric-oral Helicobacter pylori and oral hygiene in patients with vitamin B12-deficiency anemia," Oral Surgery, Oral Medicine, Oral Pathology, Oral Radiology, and Endodontics, vol. 92, no. 2, pp. 166-169, 2001.

[22] C. R. Choudhury, A. D. Choudhury, S. Alam, A. F. Markus, and A. Tanaka, "Presence of $H$. pylori in the oral cavity of betel-quid ("Paan") chewers with dyspepsia: Relationship with periodontal health," Public Health, vol. 117, no. 5, pp. 346-347, 2003.

[23] M. T. Chitsazi, E. Fattahi, R. M. Z. Farahani, and S. Fattahi, "Helicobacter pylori in the dental plaque: is it of diagnostic value for gastric infection?" Medicina Oral Patologia Oral y Cirugia Bucal, vol. 11, no. 4, pp. E325-E328, 2006.

[24] P. G. Hardo, A. Tugnait, F. Hassan et al., "Helicobacter pylori infection and dental care," Gut, vol. 37, no. 1, pp. 44-46, 1995.

[25] I. Teoman, N. Özmeriç, G. Özcan et al., "Comparison of different methods to detect Helicobacter pylori in the dental plaque of dyspeptic patients," Clinical Oral Investigations, vol. 11, no. 3, pp. 201-205, 2007.

[26] D. B. Namiot, K. Leszczyńska, Z. Namiot, M. Chilewicz, R. Bucki, and A. Kemona, "The occurrence of Helicobacter pylori antigens in dental plaque; an association with oral health status and oral hygiene practices," Advances in Medical Sciences, vol. 55 , no. 2, pp. 167-171, 2010.

[27] K. Leszczyńska, D. B. Namiot, Z. Namiot, J. K. Leszczyńska, P. Jakoniuk, and A. Kemona, "Application of immunoassay for detection of Helicobacter pylori antigens in the dental plaque," Advances in Medical Sciences, vol. 54, no. 2, pp. 194-198, 2009. 
[28] L. Checchi, P. Felice, C. Acciardi et al., "Absence of Helicobacter pylori in dental plaque assessed by stool test," American Journal of Gastroenterology, vol. 95, no. 10, pp. 3005-3006, 2000.

[29] E. Savoldi, M. G. Marinone, R. Negrini, D. Facchinetti, A. Lanzini, and P. L. Sapelli, "Absence of Helicobacter pylori in dental plaque determined by immunoperoxidase," Helicobacter, vol. 3, no. 4, pp. 283-288, 1998.

[30] A. K. Gürbüz, M. Özel, Y. Yazgan, M. Çelik, and Ş. Yildirim, "Oral colonization of Helicobacter pylori: risk factors and response to eradication therapy," Southern Medical Journal, vol. 96, no. 3, pp. 244-247, 2003.

[31] S. Agarwal and K. D. Jithendra, "Presence of Helicobacter pylori in subgingival plaque of periodontitis patients with and without dyspepsia, detected by polymerase chain reaction and culture," Journal of Indian Society of Periodontology, vol. 16, no. 3, pp. 398-403, 2012.

[32] A. Oshowo, D. Gillam, A. Botha et al., "Helicobacter pylori: the mouth, stomach, and gut axis," Annals of Periodontology, vol. 3, no. 1, pp. 276-280, 1998.

[33] M. Cześnikiewicz-Guzik, E. Karczewska, W. Bielański et al., "Association of the presence of Helicobacter pylori in the oral cavity and in the stomach," Journal of Physiology and Pharmacology, vol. 55, supplement 2, pp. 105-115, 2004.

[34] B. A. Dye, D. Kruszon-Moran, and G. McQuillan, “The relationship between periodontal disease attributes and Helicobacter pylori infection among adults in the United States," American Journal of Public Health, vol. 92, no. 11, pp. 1809-1815, 2002.

[35] M. Al Asqah, N. Al Hamoudi, S. Anil, A. Al Jebreen, and W. K. Al-Hamoundi, "Is the presence of Helicobacter pylori in the dental," Canadian Journal of Gastroenterology, vol. 23, no. 3, pp. 177-179, 2009.

[36] R. Bürgers, W. Schneider-Brachert, U. Reischl et al., "Helicobacter pylori in human oral cavity and stomach," European Journal of Oral Sciences, vol. 116, no. 4, pp. 297-304, 2008.

[37] M. Umeda, H. Kobayashi, Y. Takeuchi et al., "High prevalence of Helicobacter pylori detected by PCR in the oral cavities of periodontitis patients," Journal of Periodontology, vol. 74, no. 1, pp. 129-134, 2003.

[38] P. S. Anand, K. Nandakumar, and K. T. Shenoy, "Are dental plaque, poor oral hygiene, and periodontal disease associated with Helicobacter pylori infection?" Journal of Periodontology, vol. 77, no. 4, pp. 692-698, 2006.

[39] A. Berroteran, M. Perrone, M. Correnti et al., "Detection of Helicobacter pylori DNA in the oral cavity and gastroduodenal system of a Venezuelan population," Journal of Medical Microbiology, vol. 51, no. 9, pp. 764-770, 2002.

[40] S. Zaric, B. Bojic, L. Jankovic et al., "Periodontal therapy improves gastric Helicobacter pylori eradication," Journal of Dental Research, vol. 88, no. 10, pp. 946-950, 2009.

[41] I. Bago, J. Bago, V. Plečko, A. Aurer, K. Majstorović, and A. Budimir, "The effectiveness of systemic eradication therapy against oral Helicobacter pylori," Journal of Oral Pathology and Medicine, vol. 40, no. 5, pp. 428-432, 2011.

[42] E. C. Gebara, C. M. Faria, C. Pannuti, L. Chehter, M. P. A. Mayer, and L. A. P. A. Lima, "Persistence of Helicobacter pylori in the oral cavity after systemic eradication therapy," Journal of Clinical Periodontology, vol. 33, no. 5, pp. 329-333, 2006.

[43] H. Miyabayashi, K. Furihata, T. Shimizu, I. Ueno, and T. Akamatsu, "Influence of oral Helicobocter pylori on the success of eradication therapy against gastric Helicobacter pylori," Helicobacter, vol. 5, no. 1, pp. 30-37, 2000.
[44] J. Gao, Y. Li, Q. Wang, C. Qi, and S. Zhu, "Correlation between distribution of Helicobacter pylori in oral cavity and chronic stomach conditions," Journal of Huazhong University of Science and Technology-Medical Science, vol. 31, no. 3, pp. 409-412, 2011.

[45] F. M. Suk, S. H. Chen, Y. S. Ho et al., "It is difficult to eradicate Helicobacter pylori from dental plaque by triple therapy," Chinese Medical Journal, vol. 65, no. 10, pp. 468-473, 2002.

[46] A. K. Butt, A. A. Khan, B. A. Suleman, and R. Bedi, "Randomized clinical trial of Helicobacter pylori from dental plaque," British Journal of Surgery, vol. 88, no. 2, p. 206, 2001.

[47] C. L. Jia, G. S. Jiang, C. H. Li, and C. R. Li, "Effect of dental plaque control on infection of Helicobacter pylori in gastric mucosa," Journal of Periodontology, vol. 80, no. 10, pp. 16061609, 2009.

[48] M. B. Assumpção, L. C. Martins, H. P. M. Barbosa et al., "Helicobacter pylori in dental plaque and stomach of patients from Northern Brazil," World Journal of Gastroenterology, vol. 16, no. 24, pp. 3033-3039, 2010.

[49] A. Özdemir, M. R. Mas, S. Şahin, U. Sağlamkaya, and Ü. Ateşkan, "Detection of Helicobacter pylori colonization in dental plaques and tongue scrapings of patients with chronic gastritis," Quintessence International, vol. 32, no. 2, pp. 131-134, 2001.

[50] H. Qureshi, W. Ahmed, G. Arain, S. Syed, I. Mehdi, and S. E. Alam, "Correlation of histology, CLO, dental plaque, and saliva in patients undergoing upper GI endoscopy," American Journal of Gastroenterology, vol. 94, no. 3, pp. 861-862, 1999.

[51] Q. Q. Contractor, M. Y. Tahir, S. Naseem, and S. Ahmad, "Helicobacter pylori in the dental plaque of healthy Saudis," Saudi Journal of Gastroenterology, vol. 4, no. 1, pp. 13-16, 1998.

[52] H. Momtaz, N. Souod, H. Dabiri, and M. Sarshar, "Study of Helicobacter pylori genotype status in saliva, dental plaques, stool and gastric biopsy samples," World Journal of Gastroenterology, vol. 18, no. 17, pp. 2105-2111, 2012.

[53] S. Chaudhry, M. Idrees, M. Izhar, A. K. Butt, and A. A. Khan, "Simultaneous amplification of two bacterial genes: more reliable method of Helicobacter pylori detection in microbial rich dental plaque samples," Current Microbiology, vol. 62, no. 1, pp. 78-83, 2011.

[54] A. Wichelhaus, L. Brauchli, Q. Song, G. Adler, and G. Bode, "Prevalence of Helicobacter pylori in the adolescent oral cavity: dependence on orthodontic therapy, oral flora and hygiene," Journal of Orofacial Orthopedics, vol. 72, no. 3, pp. 187-195, 2011.

[55] L. T. Rasmussen, R. W. de Labio, L. L. Gatti et al., "Helicobacter pylori detection in gastric biopsies, saliva and dental plaque of Brazilian dyspeptic patients," Memorias do Instituto Oswaldo Cruz, vol. 105, no. 3, pp. 326-330, 2010.

[56] A. Eskandari, A. Mahmoudpour, N. Abolfazli, and A. Lafzi, "Detection of Helicobacter pylori using PCR in dental plaque of patients with and without gastritis," Medicina Oral, Patologia Oral y Cirugia Bucal, vol. 15, no. 1, pp. e28-e31, 2010.

[57] D. G. Silva, E. M. B. Tinoco, G. A. Rocha et al., "Helicobacter pylori transiently in the mouth may participate in the transmission of infection," Memorias do Instituto Oswaldo Cruz, vol. 105, no. 5, pp. 657-660, 2010.

[58] D. G. Silva, R. H. Stevens, J. M. B. MacEdo et al., "Presence of Helicobacter pylori in supragingival dental plaque of individuals with periodontal disease and upper gastric diseases," Archives of Oral Biology, vol. 55, no. 11, pp. 896-901, 2010.

[59] D. G. Silva, R. H. Stevens, J. M. B. Macedo et al., "Detection of cytotoxin genotypes of Helicobacter pylori in stomach, saliva and dental plaque," Archives of Oral Biology, vol. 54, no. 7, pp. 684-688, 2009. 
[60] L. S. Gonçalves, R. Souto, and A. P. Colombo, "Detection of Helicobacter pylori, enterococcus faecalis, and pseudomonas aeruginosa in the subgingival biofilm of hiv-infected subjects undergoing HAART with chronic periodontitis," European Journal of Clinical Microbiology and Infectious Diseases, vol. 28, no. 11, pp. 1335-1342, 2009.

[61] Y. Liu, H. Yue, A. Li et al., "An epidemiologic study on the correlation between oral Helicobacter pylori and Gastric $H$. pylori," Current Microbiology, vol. 58, no. 5, pp. 449-453, 2009.

[62] Y. Liu, H. Lin, Y. Bai et al., "Study on the relationship between Helicobacter pylori in the dental plaque and the occurrence of dental caries or oral hygiene index," Helicobacter, vol. 13, no. 4, pp. 256-260, 2008.

[63] B. J. Olivier, R. P. Bond, W. B. Van Zyl et al., "Absence of Helicobacter pylori within the oral cavities of members of a healthy south African community," Journal of Clinical Microbiology, vol. 44, no. 2, pp. 635-636, 2006.

[64] S. Kignel, F. De Almeida Pina, E. A. André, M. P. Alves Mayer, and E. G. Birman, "Occurrence of Helicobacter pylori in dental plaque and saliva of dyspeptic patients," Oral Diseases, vol. 11, no. 1, pp. 17-21, 2005.

[65] A. M. Fritscher, K. Cherubini, J. Chies, and A. C. O. Dias, "Association between Helicobacter pylori and recurrent aphthous stomatitis in children and adolescents," Journal of Oral Pathology and Medicine, vol. 33, no. 3, pp. 129-132, 2004.

[66] E. C. Gebara, C. Pannuti, C. M. Faria, L. Chehter, M. P. A. Mayer, and L. A. P. A. Lima, "Prevalence of Helicobacter pylori detected by polymerase chain reaction in the oral cavity of periodontitis patients," Oral Microbiology and Immunology, vol. 19, no. 4, pp. 277-280, 2004.

[67] C. Goosen, J. Theron, M. Ntsala et al., "Evaluation of a novel heminested PCR assay based on the phosphoglucosamine mutase gene for detection of Helicobacter pylori in saliva and dental plaque," Journal of Clinical Microbiology, vol. 40, no. 1, pp. 205-209, 2002.

[68] Q. Song, T. Lange, A. Spahr, G. Adler, and G. Bode, "Characteristic distribution pattern of Helicobacter pylori in dental plaque and saliva detected with nested PCR," Journal of Medical Microbiology, vol. 49, no. 4, pp. 349-353, 2000.

[69] Q. Song, A. Spahr, R. M. Schmid, G. Adler, and G. Bode, "Helicobacter pylori in the oral cavity: high prevalence and great DNA diversity," Digestive Diseases and Sciences, vol. 45, no. 11, pp. 2162-2167, 2000.

[70] Q. Song, B. Haller, D. Ulrich, A. Wichelhaus, G. Adler, and G. Bode, "Quantitation of Helicobacter pylori in dental plaque samples by competitive polymerase chain reaction," Journal of Clinical Pathology, vol. 53, no. 3, pp. 218-222, 2000.

[71] Q. Song, B. Haller, R. M. Schmid, G. Adler, and G. Bode, "Helicobacter pylori in dental plaque. A comparison of different PCR primer sets," Digestive Diseases and Sciences, vol. 44, no. 3, pp. 479-484, 1999.

[72] N. P. Mapstone, D. A. F. Lynch, F. A. Lewis et al., "Identification of Helicobacter pylori DNA in the mouths and stomachs of patients with gastritis using PCR," Journal of Clinical Pathology, vol. 46, no. 6, pp. 540-543, 1993.

[73] A. M. Nguyen, L. Engstrand, R. M. Genta, D. Y. Graham, and F. A. K. El-Zaatari, "Detection of Helicobacter pylori in dental plaque by reverse transcription-polymerase chain reaction," Journal of Clinical Microbiology, vol. 31, no. 4, pp. 783-787, 1993.

[74] B. W. Loster, M. Czesnikiewicz-Guzik, W. Bielanski et al., "Prevalence and characterization of Helicobacter pylori $(H$. pylori) infection and colonization in dentists," Journal of Physiology and Pharmacology, vol. 60, supplement 8, pp. 13-18, 2009.

[75] M. Czesnikiewicz-Guzik, W. Bielanski, T. J. Guzik, B. Loster, and S. J. Konturek, "Helicobacter pylori in the oral cavity and its implications in gastric infection, periodontal health, immunology and dyspepsia," Journal of Physiology and Pharmacology, vol. 56, supplement 6, pp. 77-89, 2005.

[76] S. Agüloğlu, M. Turhanoğlu, S. Eskimez, and I. Tacir, "Detection of Helicobacter pylori colonization in human dental plaques and saliva of patients with chronic gastritis," Biotechnology and Biotechnological Equipment, vol. 20, no. 2, pp. 173-178, 2006.

[77] D. B. Namiot, Z. Namiot, A. Kemona, R. Bucki, and M. Gotębiewska, "Oral health status and oral hygiene practices of patients with peptic ulcer and how these affect Helicobacter pylori eradication from the stomach," Helicobacter, vol. 12, no. 1, pp. 63-67, 2007. 


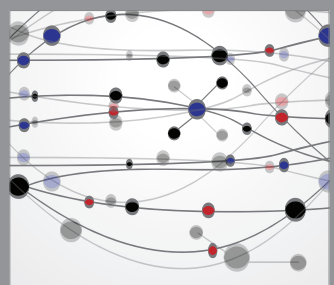

The Scientific World Journal
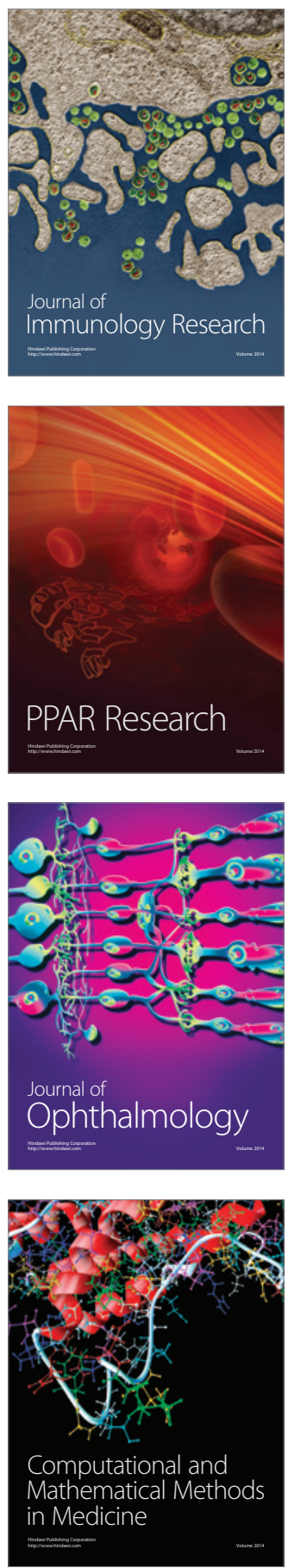

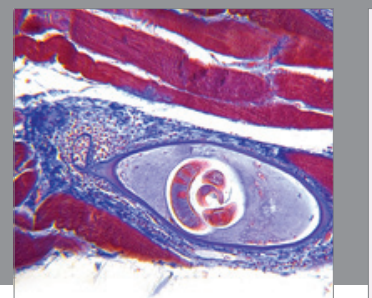

Gastroenterology

Research and Practice
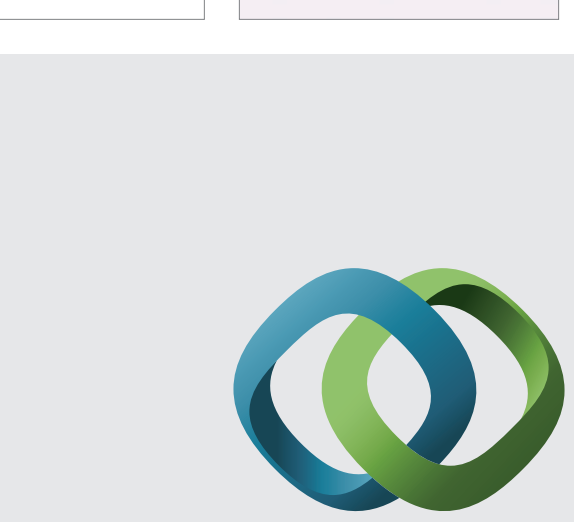

\section{Hindawi}

Submit your manuscripts at

http://www.hindawi.com
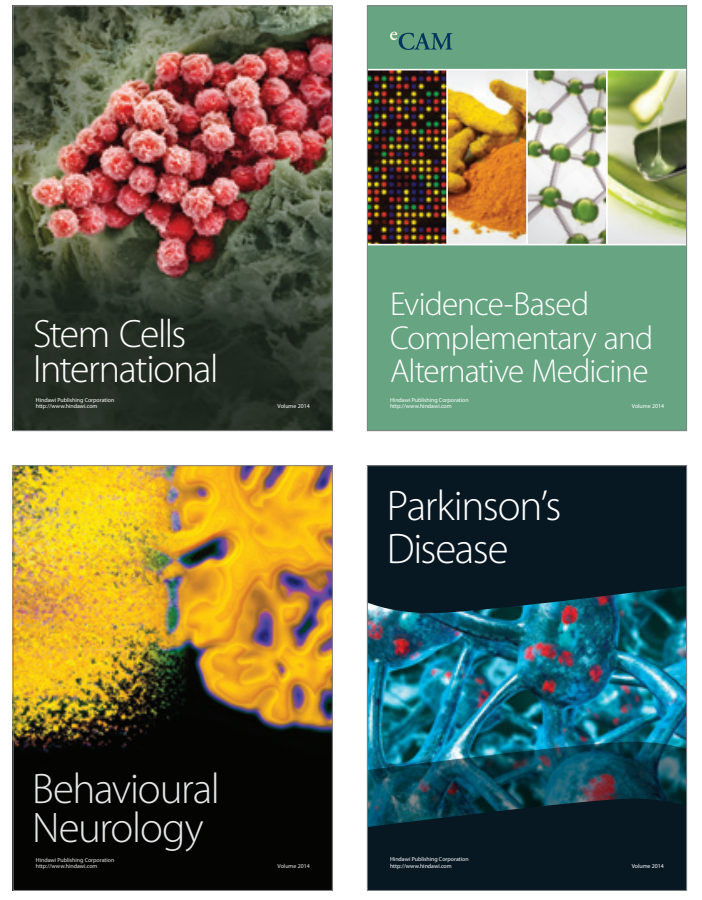
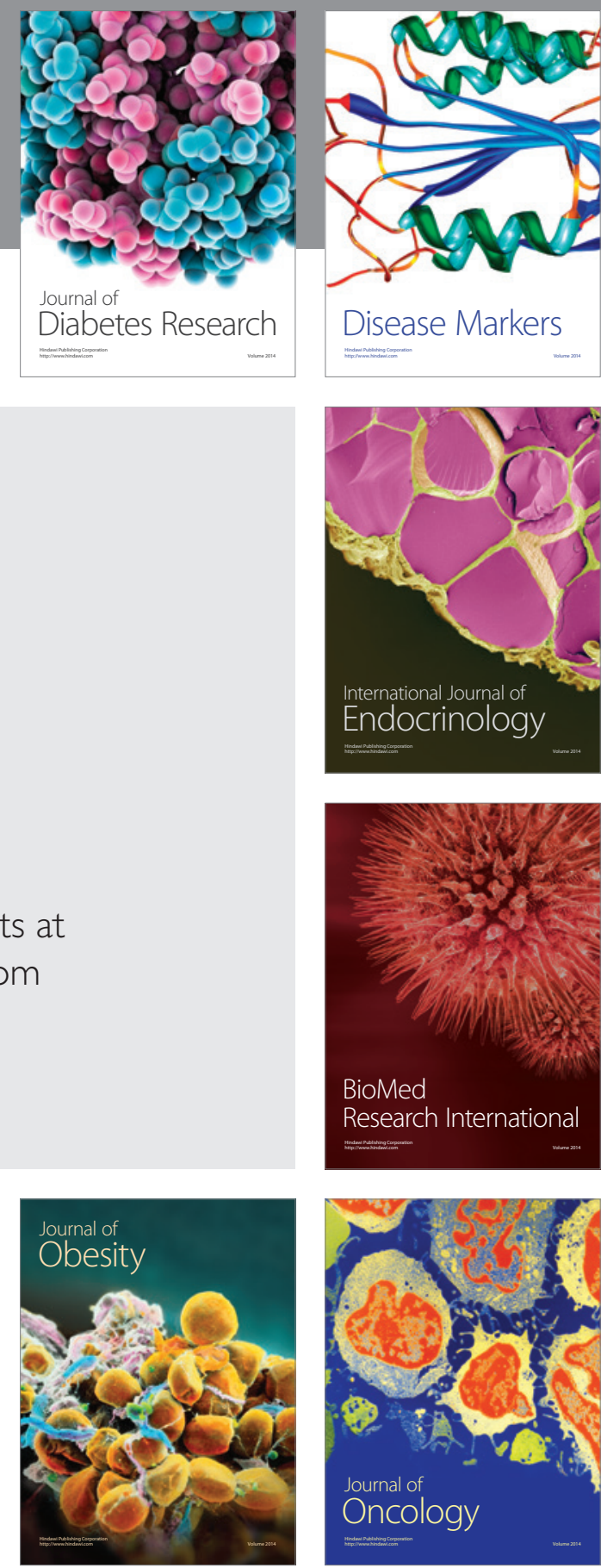

Disease Markers
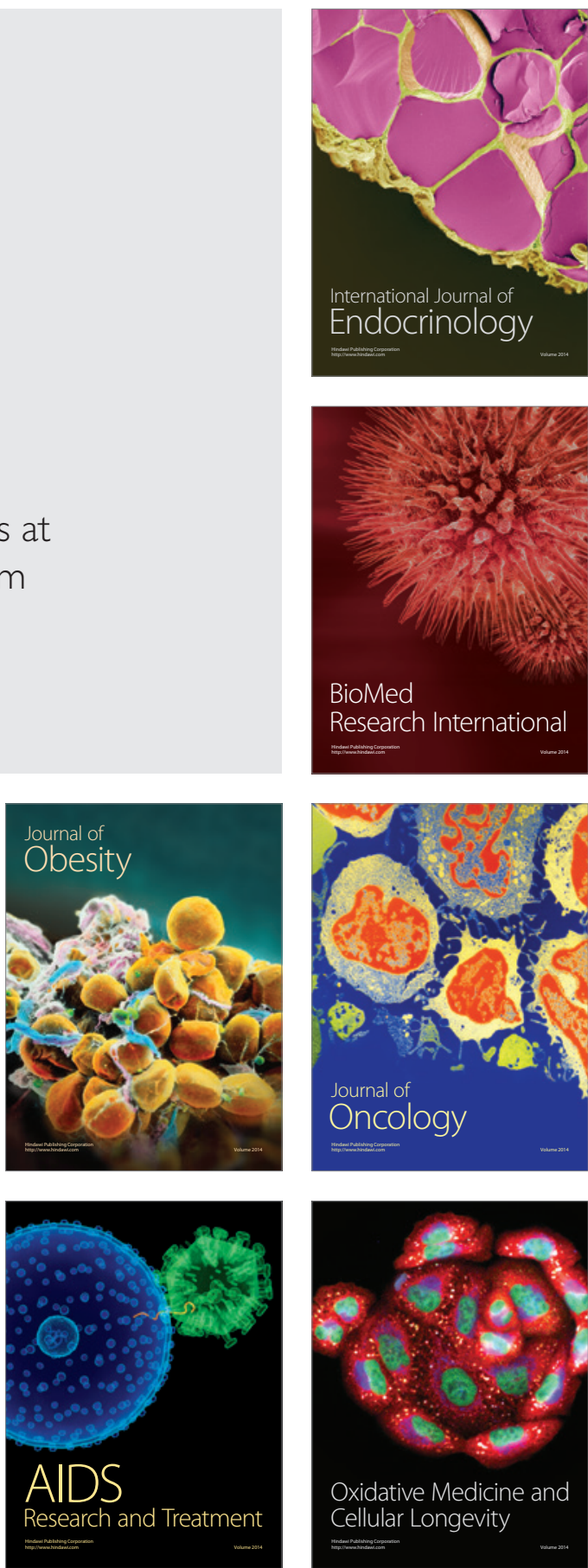